\title{
اضطرابات التكامل الحسى لدى الصم وضعاف السمع فى ضوء بعض المتغيرات
}

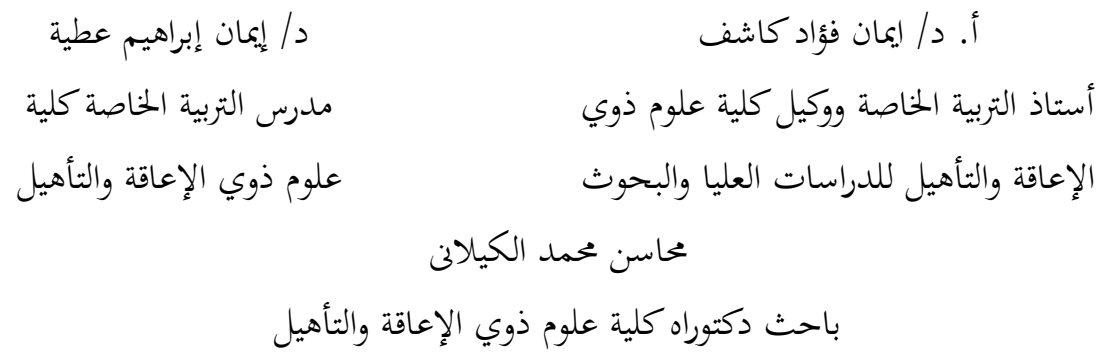


استهدف البحث التعرف على مستويات اضطراب التكامل الحسى لدى التلاميذ الصم

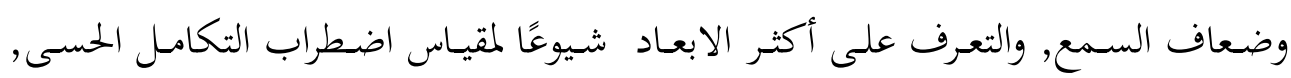

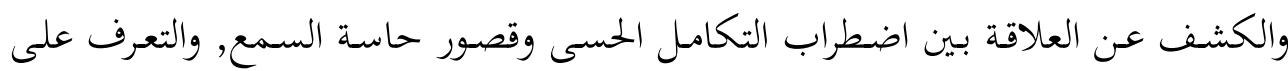

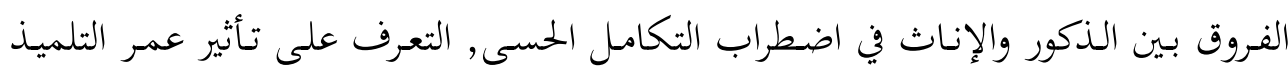

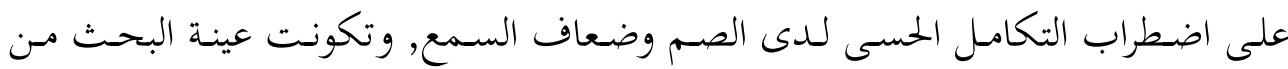

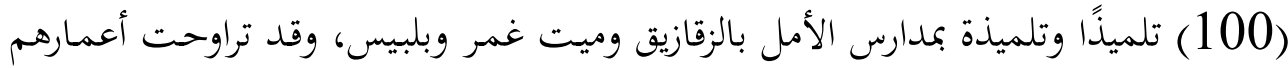

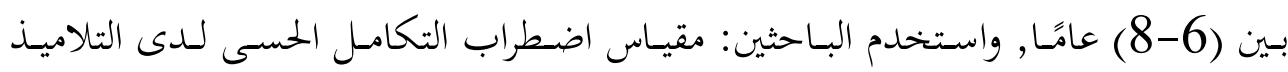

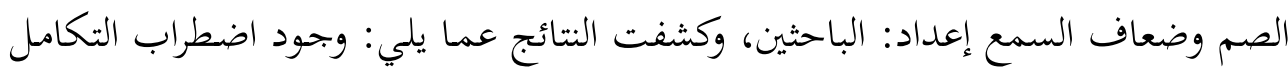

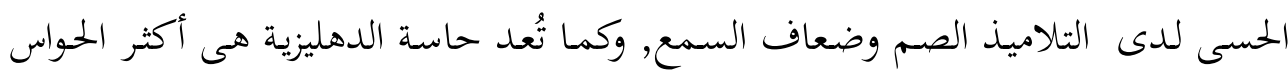

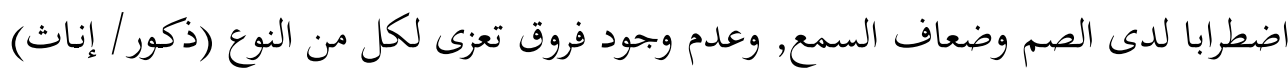

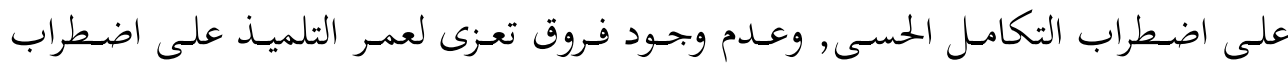

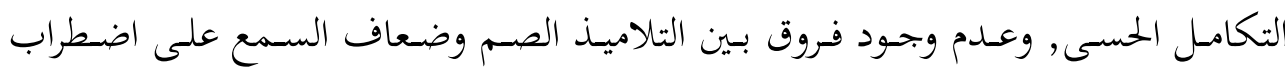

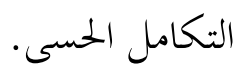
الكلمات المفتاحية: اضطراب التكامل الحسى - الصم - ضعاف السمع. 
abstract:

The study aimed to reveal the levels of sensory integration disorder in deaf and hearing impaired pupils, to identify the most common dimensions of the sensory integration disorder scale, to explore the relationship between sensory integration disorder and the hearing sense deficiency, to know the differences between males and females in the sensory integration disorder, and to identify the effect of age The pupil on the sensory integration disorder in the deaf and hearing impaired, the study sample consisted of (100) male and female pupils in the Al amal schools in Zagazig, Mit Ghamr and Belbeis, and their ages ranged between (6-8) years, the researchers used the disorder of sensory integration scale among the deaf and hearing impaired pupils.: Prep. Researchers. The results revealed the following: there is sensory integration disorder among deaf and hearing impaired pupils, the vestibular sense is the most disturbing sensation in the deaf and hearing impaired, there aren't differences attributable to each type (male / female) on the sensory integration disorder, there aren't differences due to the age of the pupils on the sensory integration disorder scale, and there aren't of differences between the deaf and hearing impaired pupils on the sensory integration disorder.

Keywords: sensory integration disorder - deaf - hard of hearing. 
يعتمـد إدراك الإنسان لعالمه على المعلومات التي يستقبلها عبر حواسه, ووجيود أي

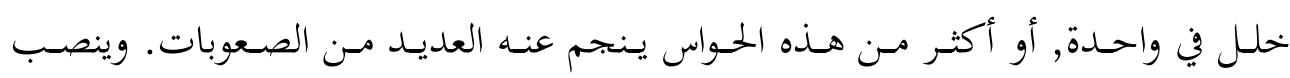

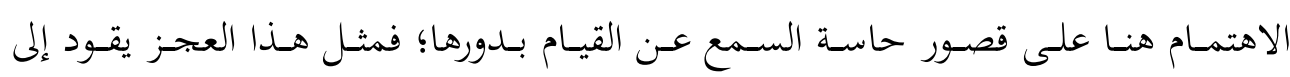

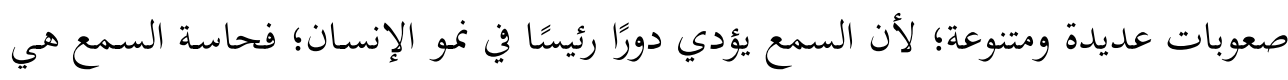

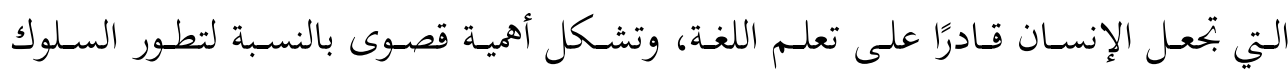

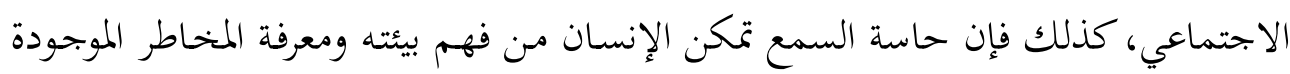

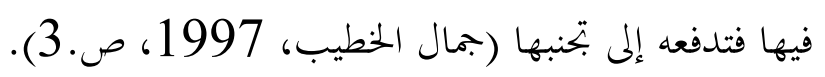

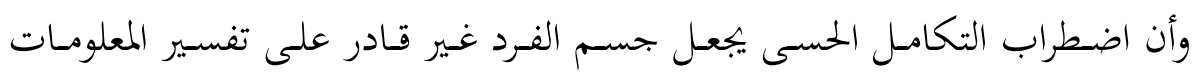

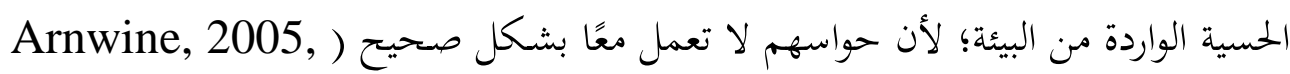

فاضطراب التكامـل الحسى يجعـل الطفـل غير قادر على تنظيم المعلومـات الحسية

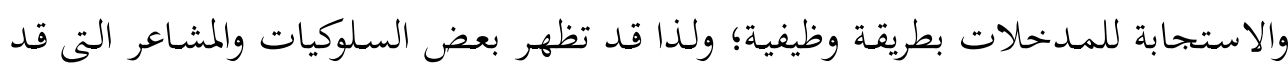
تبدو غريبة ولا تحد لها تفسير منطقى(Isbell, \& Isbell, 2007, p.19).

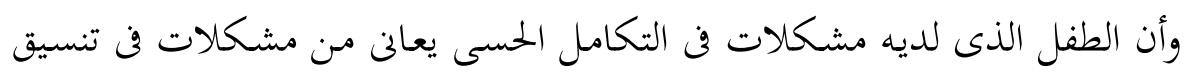

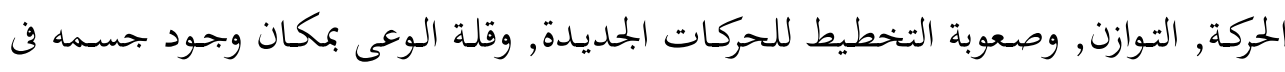

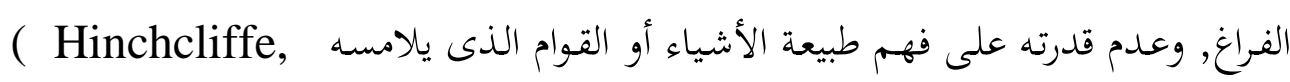
.2007, p.173) وكما ذكر Simpson (2013, p.7) أن الأطفال الذين يعانون من اضطراب التكامل الحسى يواجهوا مشكلات عديدة في بحالات النمو كالمهارات التكيفية (الأكل,

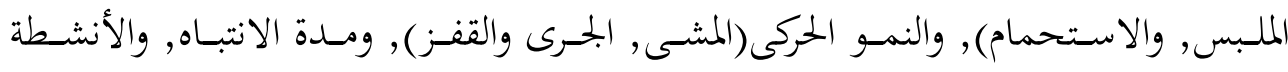

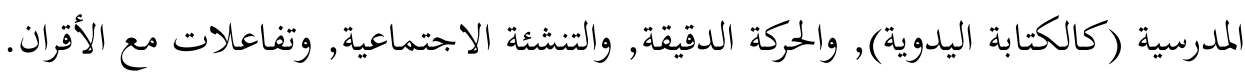
وقد أكدت دراسة كل من: \& \& \& Medendorp (2018) ;Bergeson, Houston and Miyamoto(2010); Bharadwaj, Danial and Matzke(2009); Bharadwaj, Matzke and Daniel, (2012); Gheysen and Loots( 2008); Schlumberger, Narbona and Manrique, (2004); kegel, Dhooge \&Waelvelde 
(2008) أن الأطفال الصم وضعاف السمع يعانون من اضطرابات التكامل الحسى مثل:

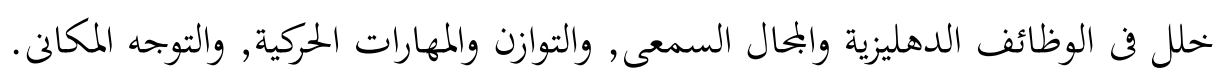

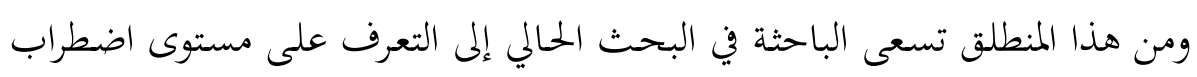
التكامل الحسى لدى الصم وضعاف السمع.

\section{مشكلة البحث}

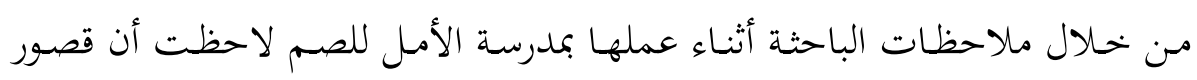

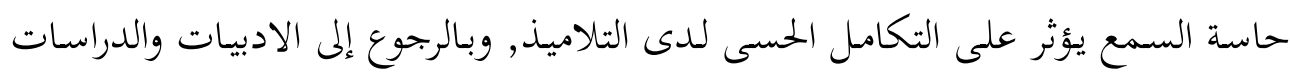

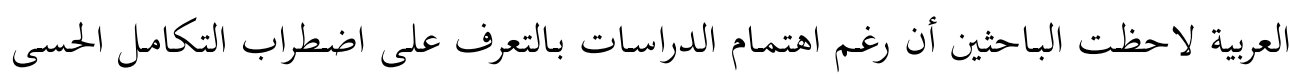

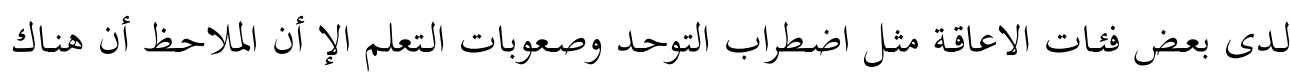

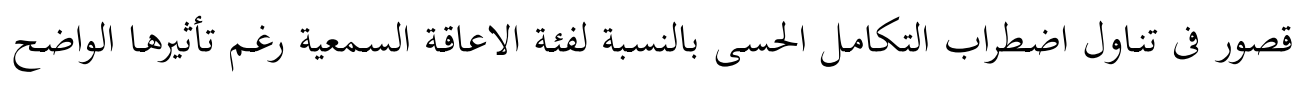

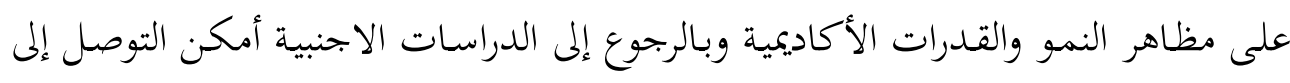

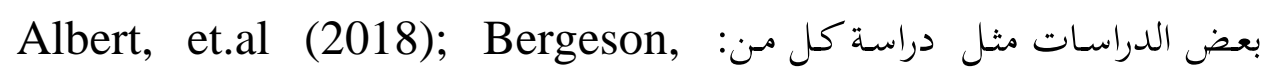
et.al(2010); Bharadwaj, et.al (2009); Bharadwaj, et.al (2012); Gheysen and Loots( 2008); Schlumberger, et.al (2004); kegel, et.al(2008) والتى ظهرت نتائجها أن هناك قصور لدى فئة المعاقين سمعيًا فن مستويات

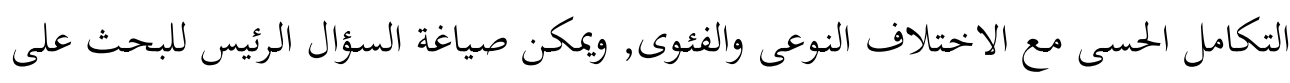

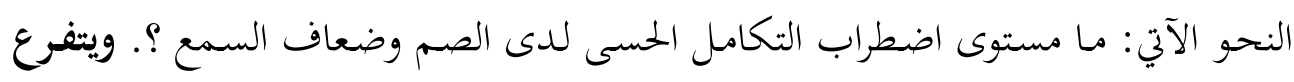

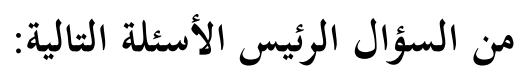

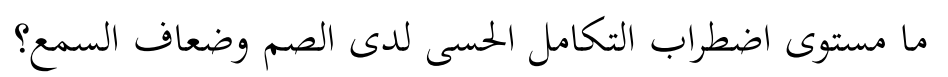

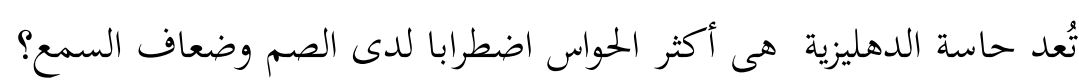

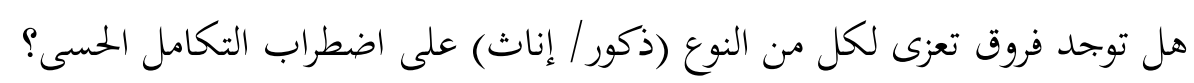

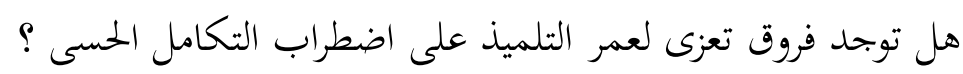

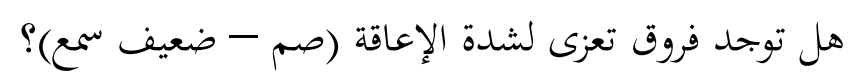


يسعى البحث الحلالى إلى ما يأتي:

التعرف على مستويات اضطراب التكامل الحسى لدى التلاميذ الصم وضعاف السمع.

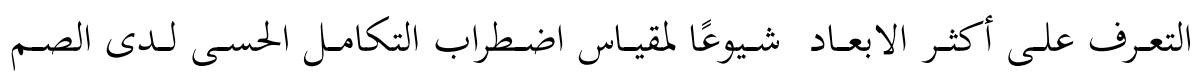

وضعاف السمع.

الكشف عن العلاقة بين اضطراب التكامل الحسى وقصور حاسة السمع.

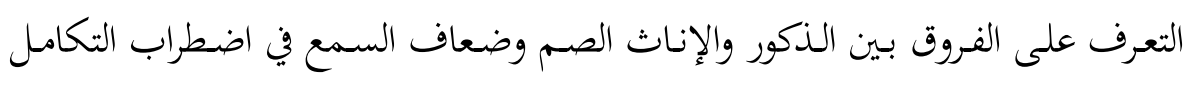

الحسى.

التعرف على تأثير عمر التلميذ على اضطراب التكامل الحسى لدى الصم وضعاف

$$
\text { السمع. (2) (n) }
$$

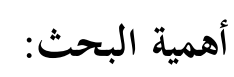

يستمد البحث الحالى الحالية أهميته من النقاط الآتية:

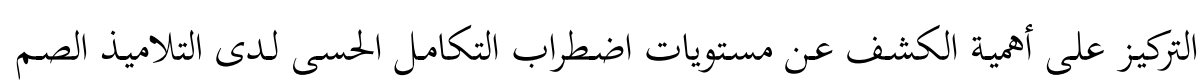

وضعاف السمع.

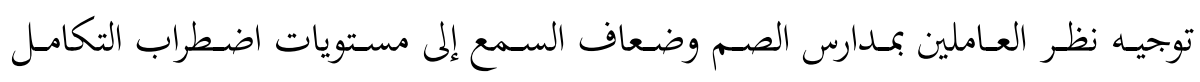

$$
\text { الحسى لدى التلاميذ الصم وضعاف السمع. }
$$

تأتى أهمية البحث من كون العينة من الصمى وضعاف السمع في في المرحلة الأبتدائية ؛ فهم

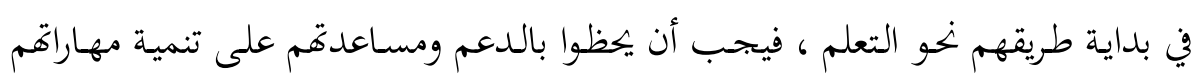

$$
\text { وقدرات التكامل الحسى. }
$$

دراسة مستوى اضطراب التكامل الحسى يسهم في وضع الاستراتيجيات التعليمية الملائمة

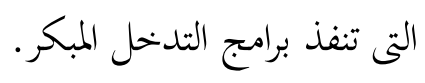




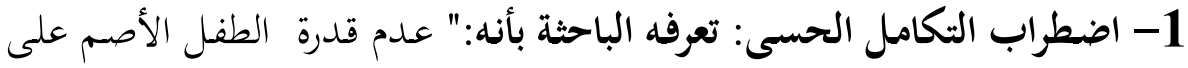

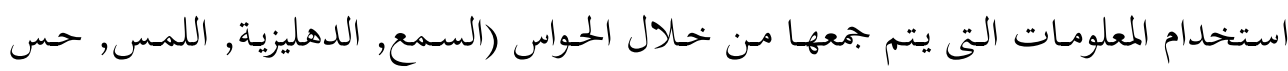
حركى العميق, البصر , الشم, التذوق) في حياتة اليومية بشكل فعال".

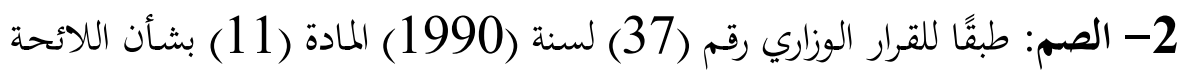

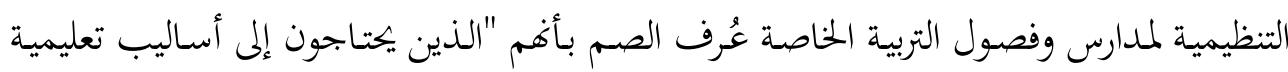

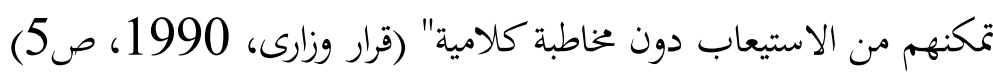

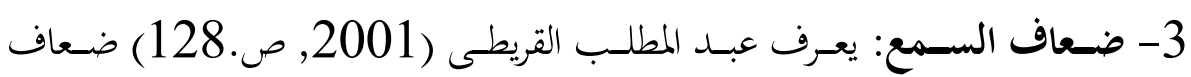

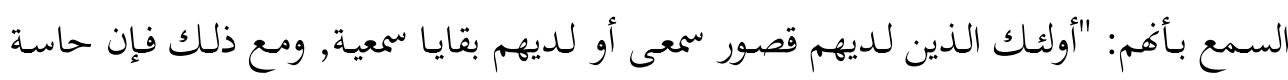

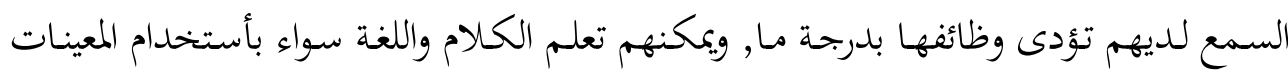

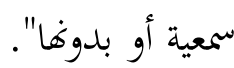

$$
\text { محددات البحث: }
$$

تتلخص محددات البحث فيما يأتي:

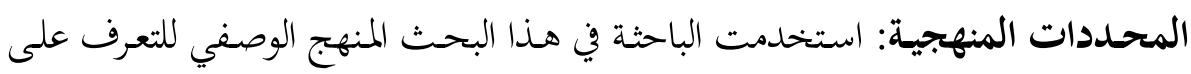
مستويات اضطراب التكامل الحسى لدى الصم وضعاف السمع.

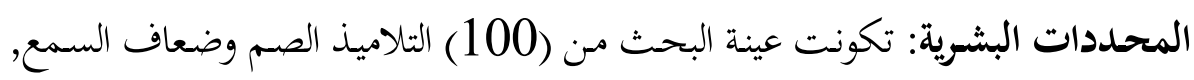
وتتراوح أعمارهم بين (6-8). المحددات المكانيسة: طبقت الأدوات على عينة البحث بمدارس الأمل للصـم وضعاف السمع بالزقازيق وبلبيس وميت غمر.

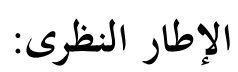

$$
\text { تعريف الصم وضعاف السمع: }
$$

اتفق كل من(2012) Mahendra \& Sulabha (2014) (

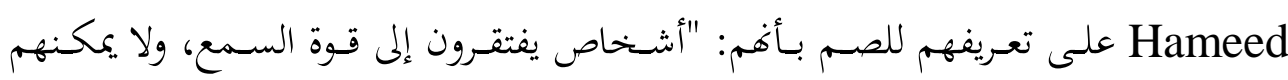


الانتفاع بحاسة السمع في أغراض الحياة اليومية، كما أفم غير قادرين على سمع وفهم الكلام سواء باستخدام السماعات أم بدونها".

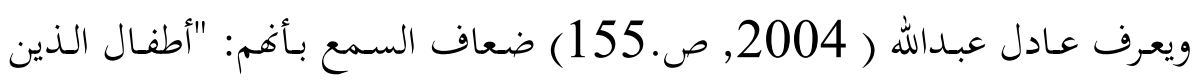

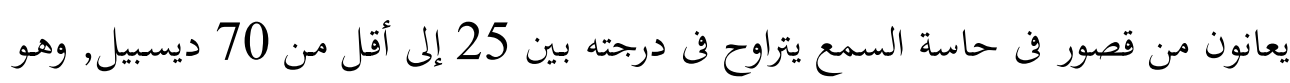

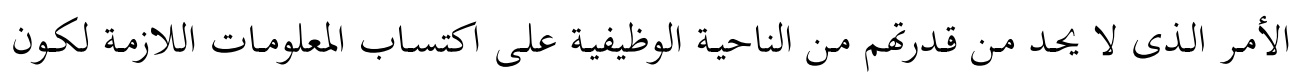

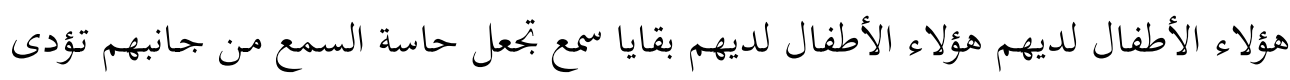
وظيفتها ما دام مصدر الصوت في حدود قدرقم السمعية.

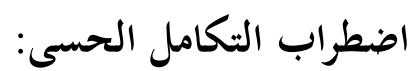

عرفت Ayres (2005, p.17 اضطراب التكامل الحسى بأنه: "هو اضطراب

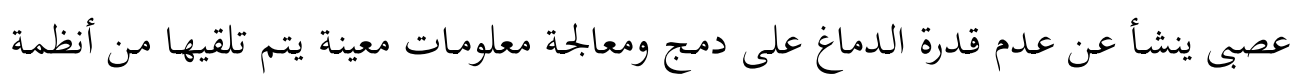
الحس؛ لذا قد تظهر بعض السلوكيات".

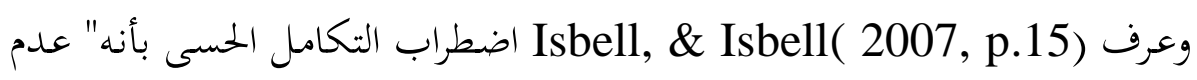

قدرة الدماغ على تنظيم الأشارات الحسية والاستجابة لما بشكل فعال, وصعوبة استخدام

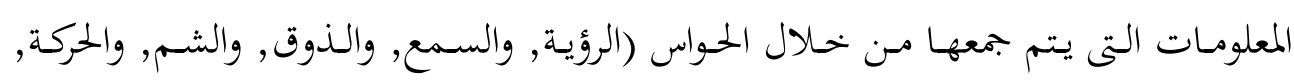
والوعى بالجسم) في الحياة اليومية ".

\section{نظرية التكامل الحسى:}

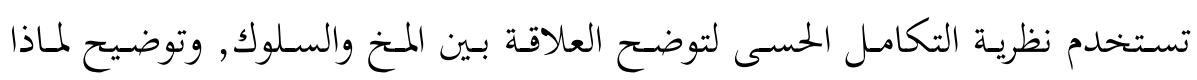

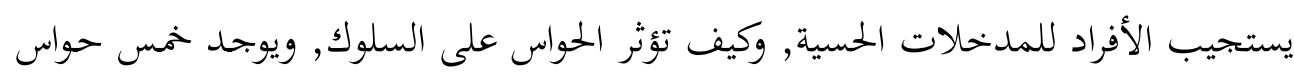

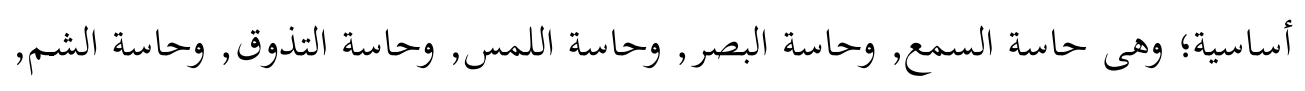
بالأضافة إلى أثنين من الحواس المهمة وهما:

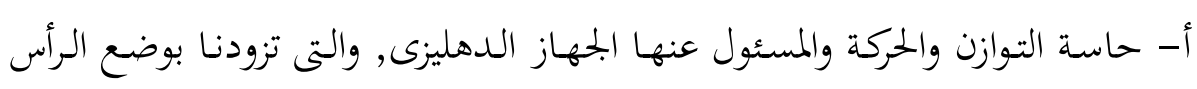

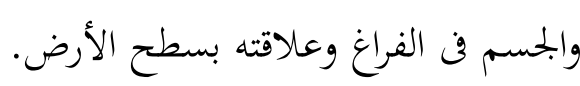




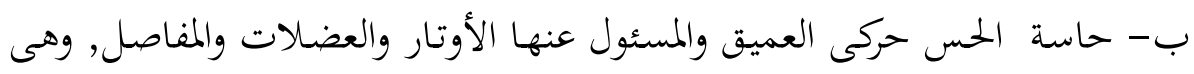

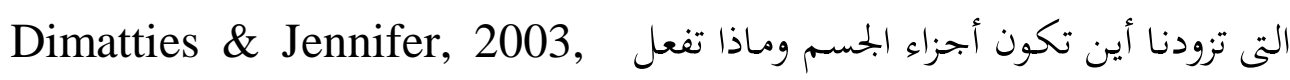
.Isbell\& Isbell, 2007, PP.12-13 ؛p.3)

ويبنى التكامل الحسى على خمس إفتراضات فى التطور العصبى:

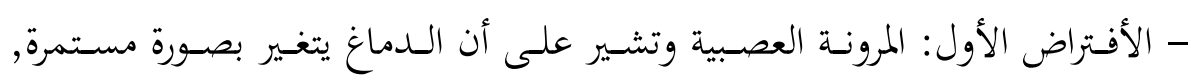

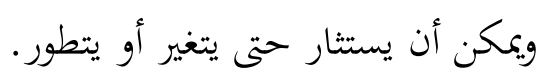

- الأفتراض الثاني: التتابع النمائى إذ أن كل سلوك متك متعلم يصبح أساس للسلوك

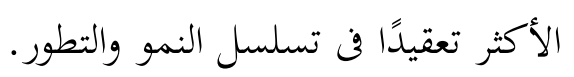

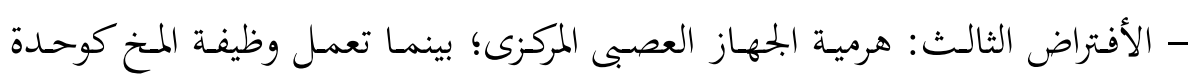

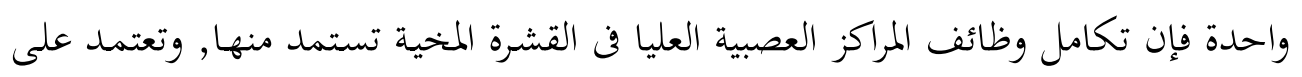

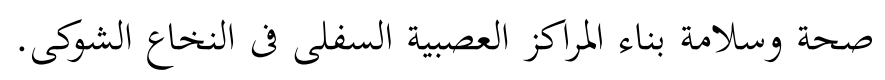

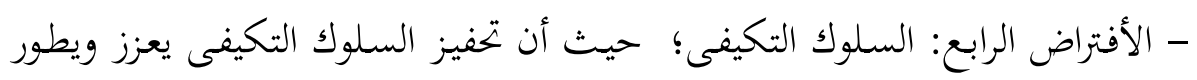

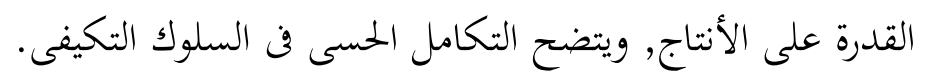

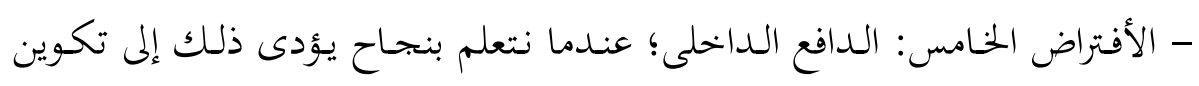
دافعية للرغبة فن زيادة التعلم(Kinnealey, Miller,1993, pp.474-482).

\section{المؤشرات التى تدل على ضعف التكامل الحسى:}

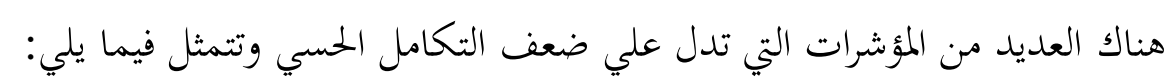

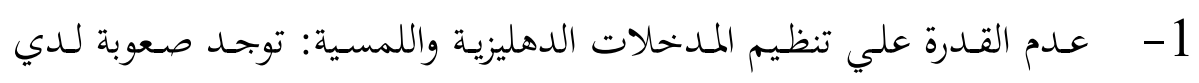

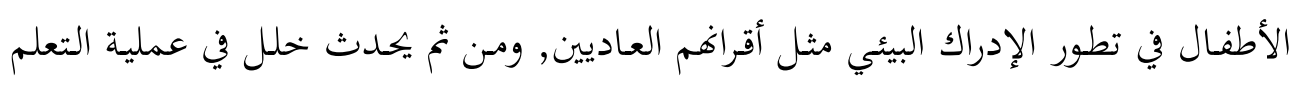

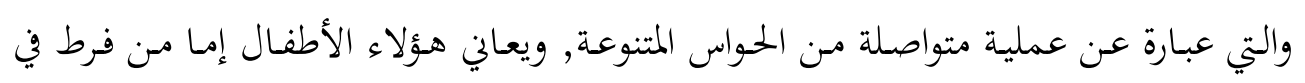

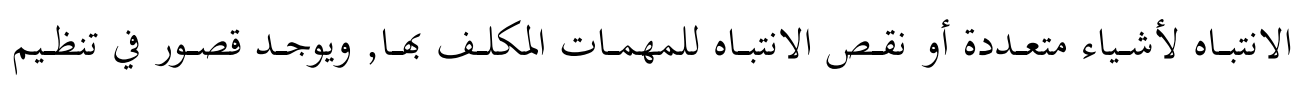

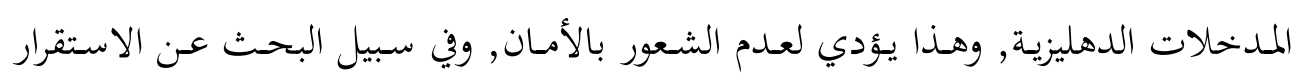

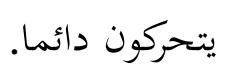




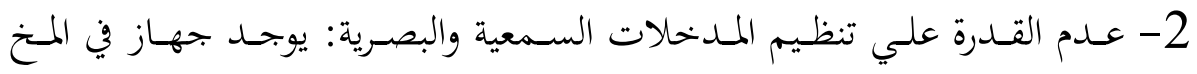

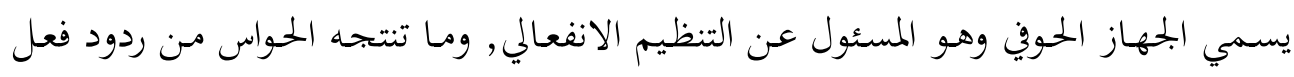

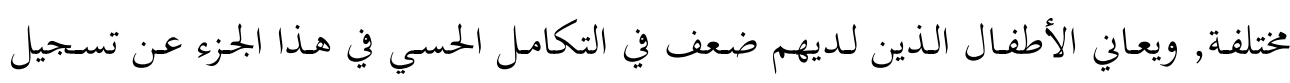

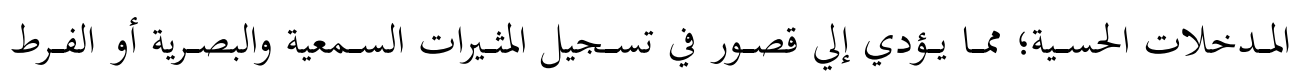

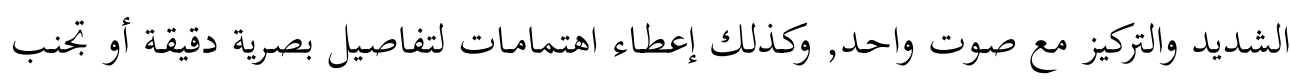
النظر للأشخاص.

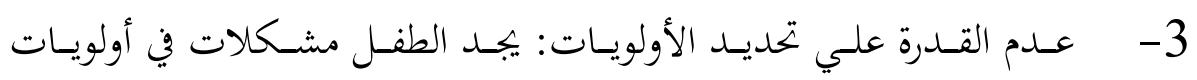

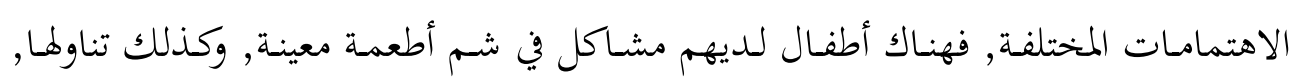

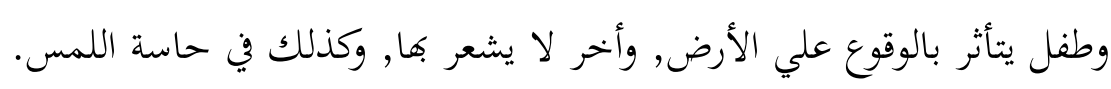

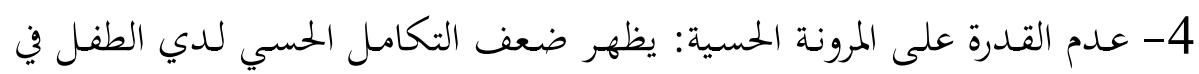

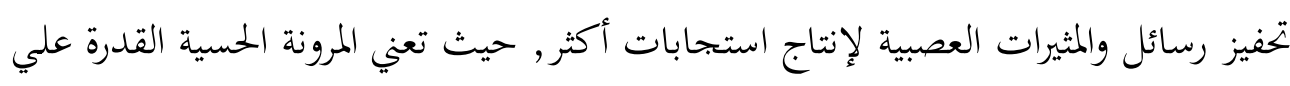

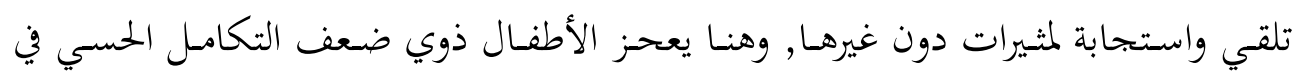

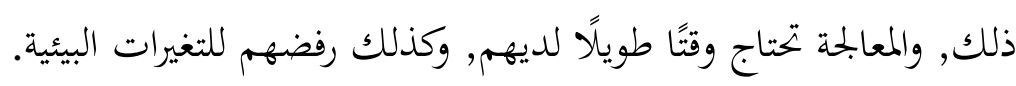

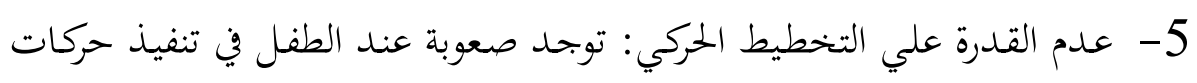

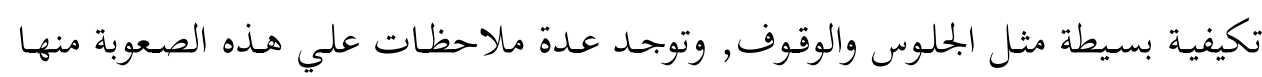

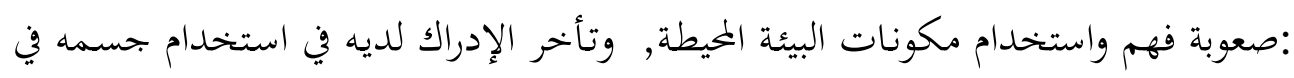

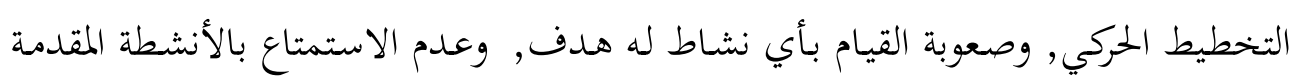

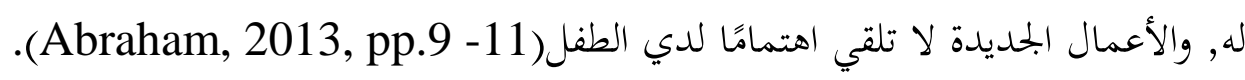

\section{مشكلات النكامل الحسى لدى الصم:-}

أشارت دراسة Diekmann, Walger,Von \& Wedel(1994 إلى الروائح

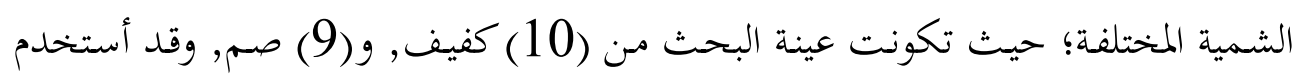

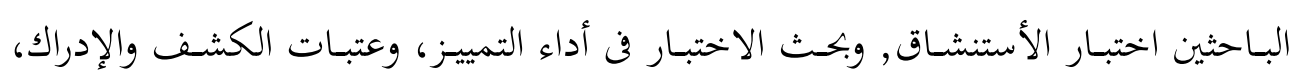

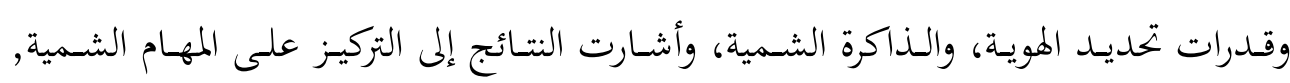

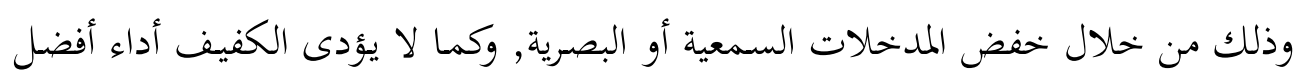




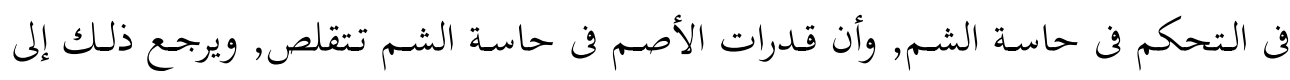
تأخر اكتساب اللغة.

وقد أشارت دراسة (2002) Mafong, Pletcher, Hoyt, \& Lalwani

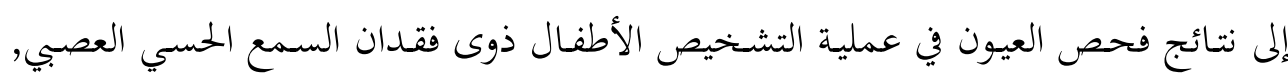

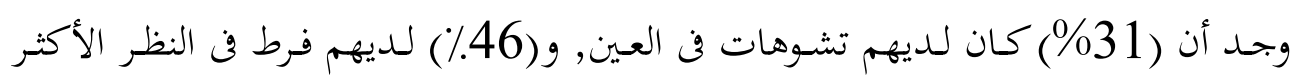

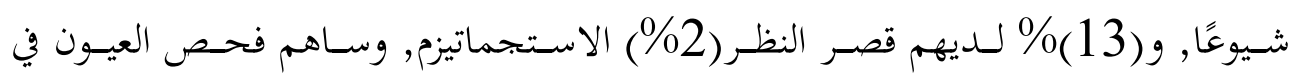
تشخيص الأطفال ذوى متلازمة فقدان السمع.

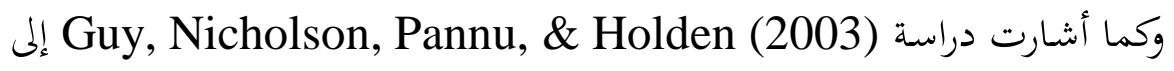
أن أكثر من (40) \% من الأطفال الصم وضعاف السمع, والبالغ عددهم (203 (110) طفلًا

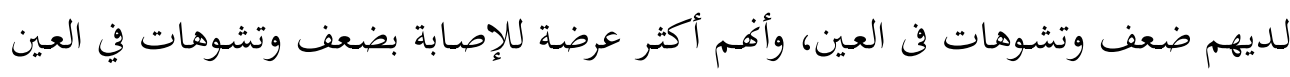

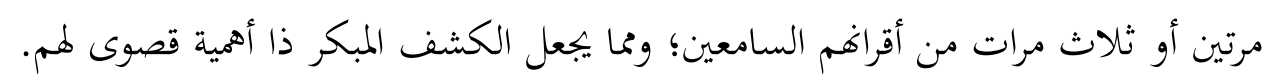

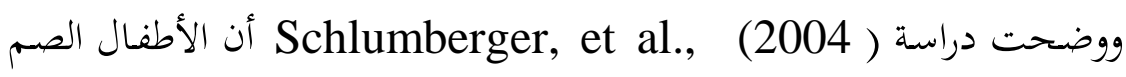

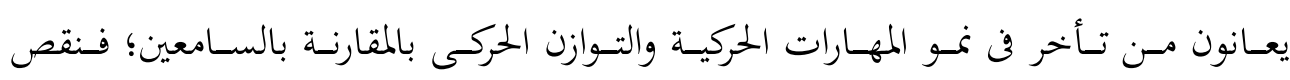

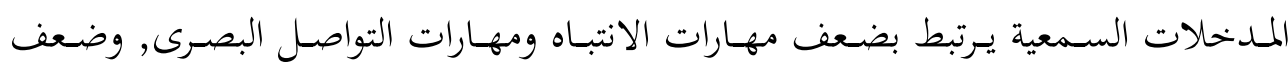
القدره على التحكم.

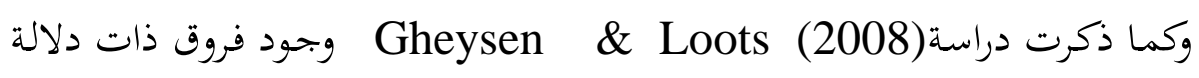

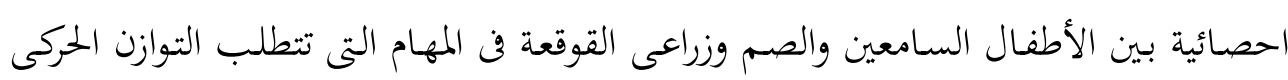

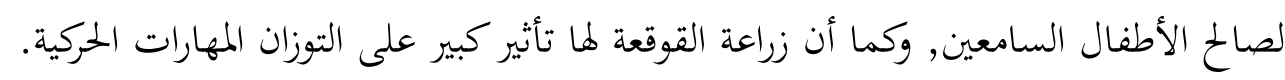

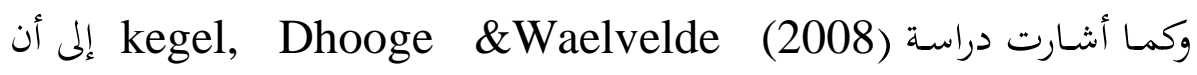

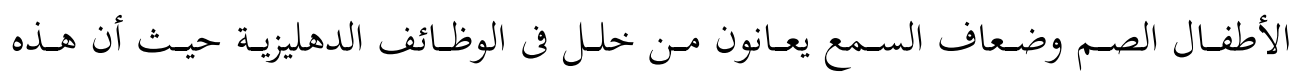

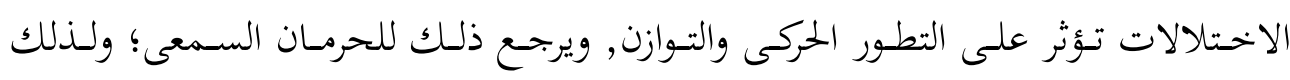

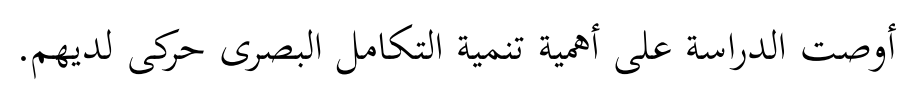

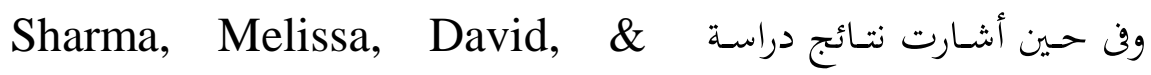

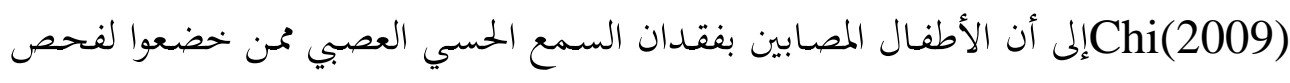

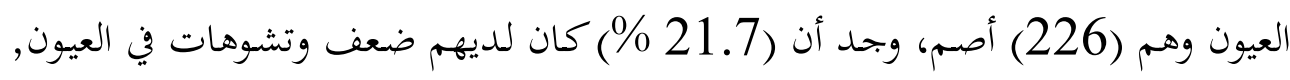


و(10.2\%) لديهم اخطاء انكسارية, و (12.8 \%) حالات غير انكسار, و(2.2 \%

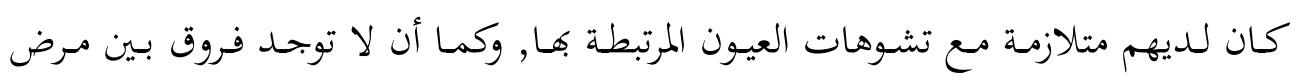

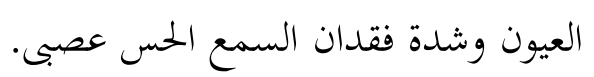

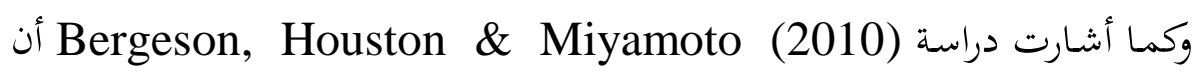

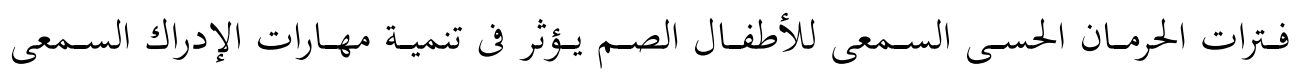

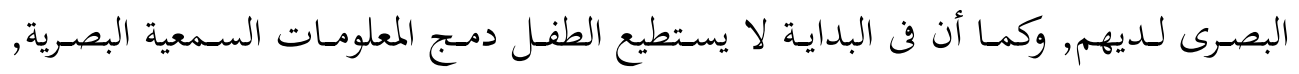

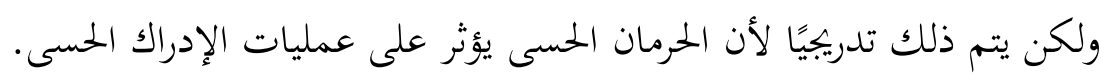

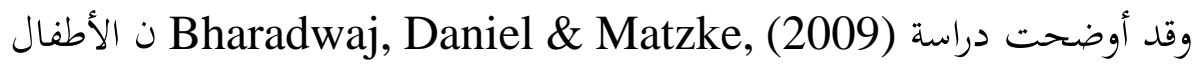
الصم وضعاف السمع يعانون من اضطرابات التكامل الحسى حيث أظهر الأطفال اضطراب

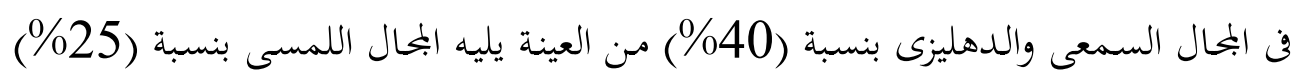

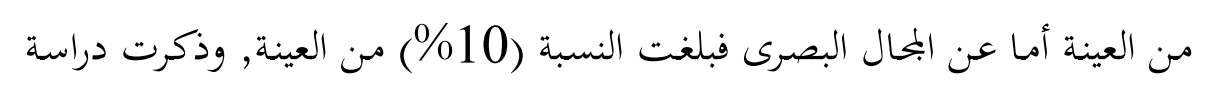
(Bharadwaj, Matzke ～\& Daniel (2012) من خلل فن الوظائف الدهليزية. وقد أشارت منظمة National Institute on Deafness and Other Communication Disorders, (2012, p.1)

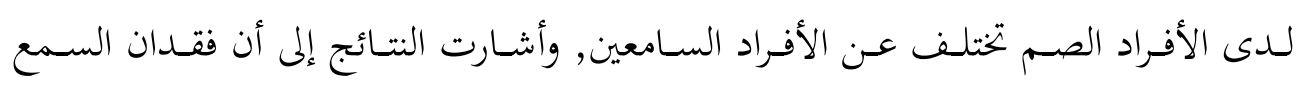
والشعور بحاسة اللمس في وقت مبكر يؤثر على نمو الدماغ.

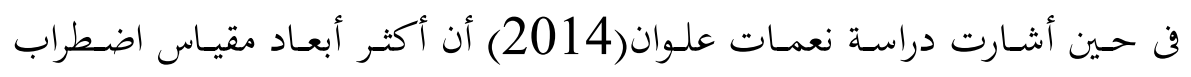

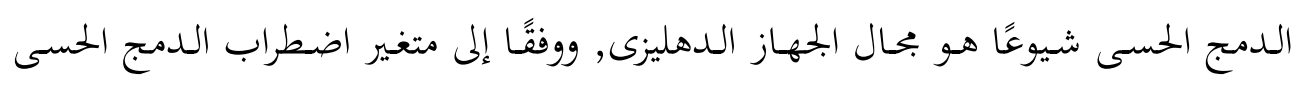

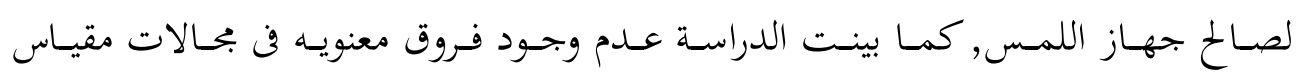

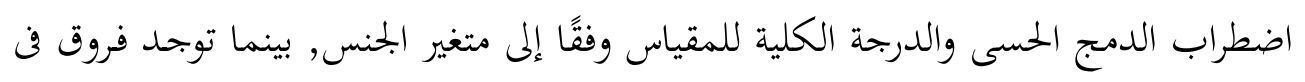

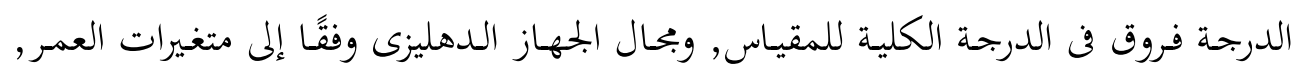

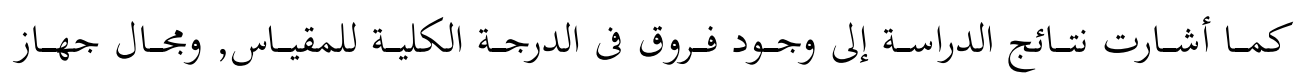

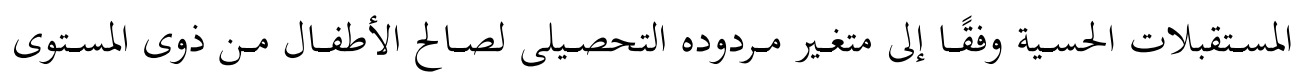

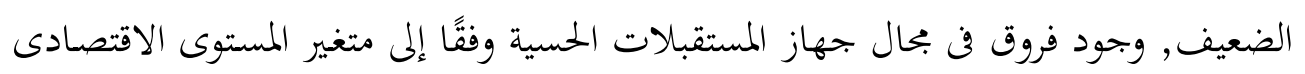


لصالح الأطفال من ذوى المستوى الضعيف, بينما لا توجد فروق جوهرية فن بحالات مقياس اضطراب الدمج الحسى والدرجة الكلية.

وأوضحت دراسة Hollingsworth, Ludlow, WilkinsCalver, \& Allen,

(2014) شيوع العيوب البصرية بين الأفراد الصم, وتتمثل هذه العيوب ف ماسلة ما يلى: خطأ

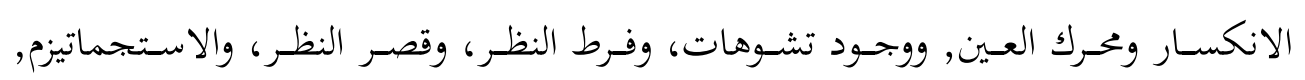

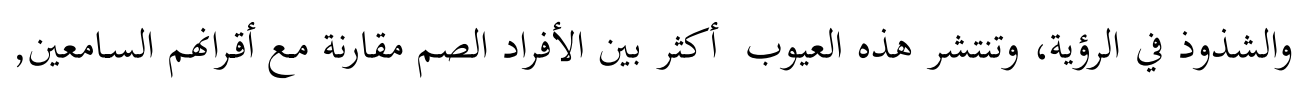

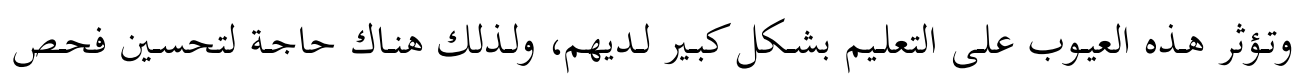

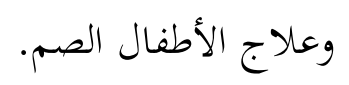

وأشارت دراسة Yogeswari, Subramanian, Sravya, \& Anandan

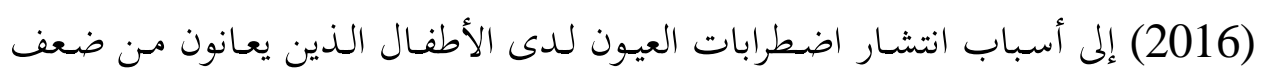

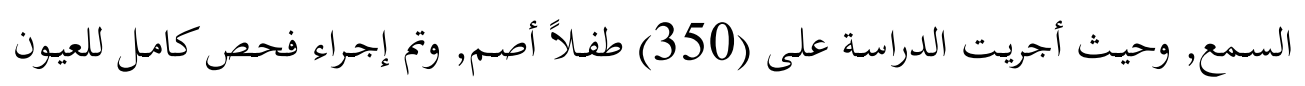

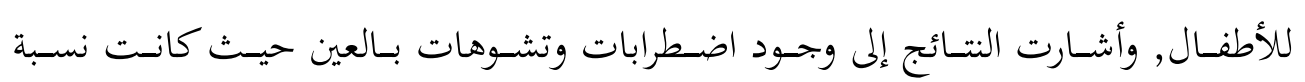

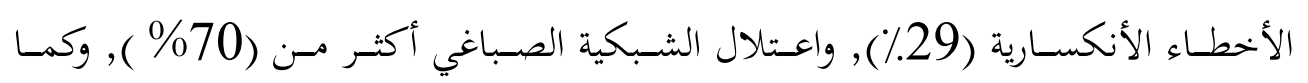

أشارت الدراسة إلى انتشار اضطرابات العيون في مدارس الصم مقارنة بمدارس السامعين.

وحاولت دراسة Park, Byeon, Park, Kim, Lee, Han \& Ban

(2017) التعرف علي العلاقة بين ضعف حاسة الشم, والفقد السمعي, وخلل النطق لدي

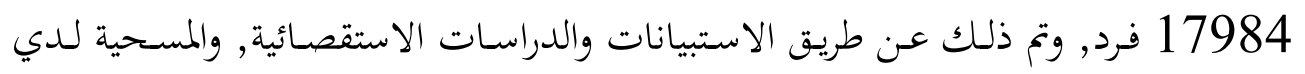

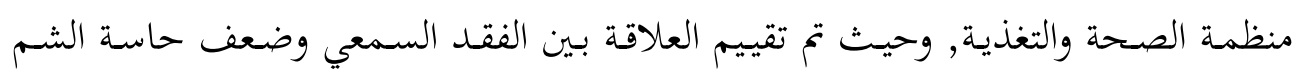

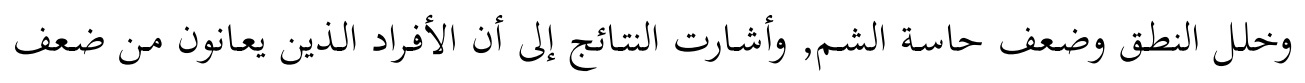

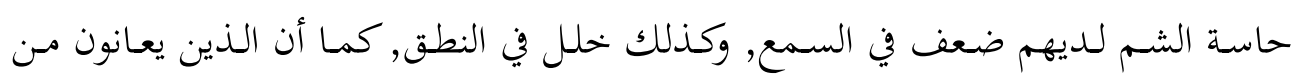

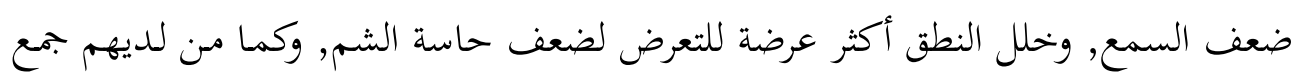

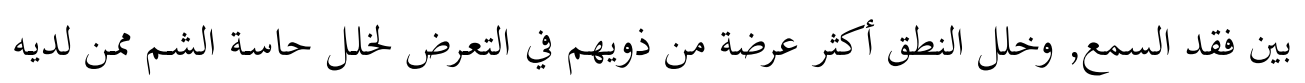
ضعف واحد فقط.

Albert, Selen, Verhagen, Pennings \& وكما أشارت نتائج دراسة فئ Medendorp (2018) 
في الحفاظ على التوازن الحركى فن الظلام, وأوصت الدراسة بتطوير برامج إعـادة التأهيل الفردى لتحسين التكامل السمعى الحركى لديهم.

Güdücü, Ergönül, Öniz, İkiz, \& Özgören, (2019) وقامت دراسي

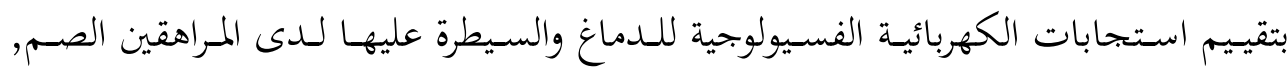

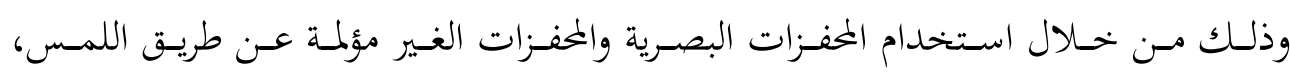

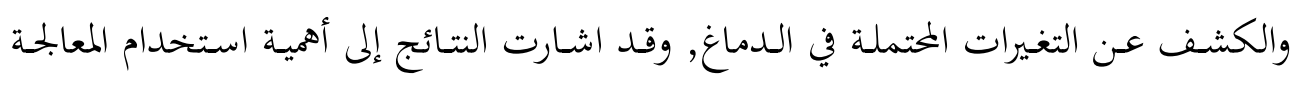

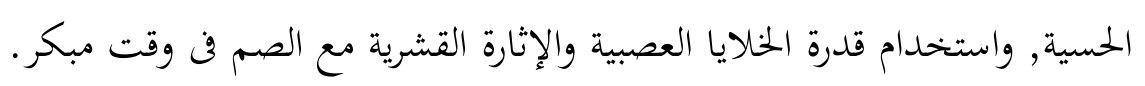

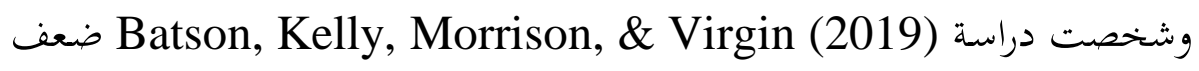

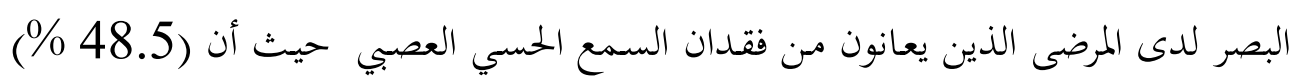

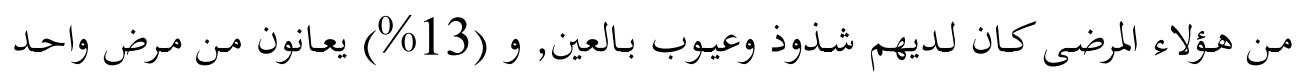

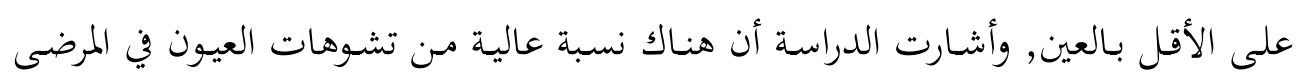
الذين يعانون من ضعف فقدان السمع الحسى.

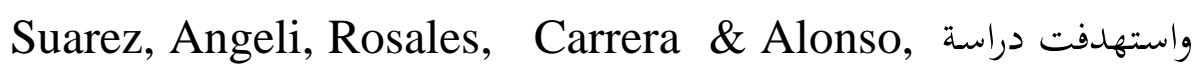

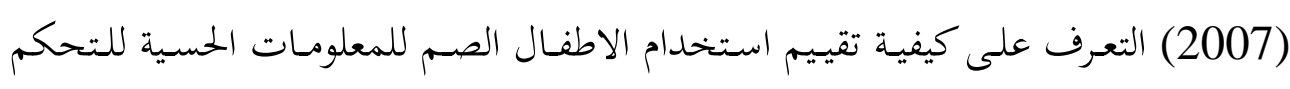

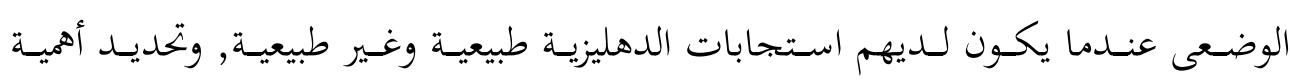

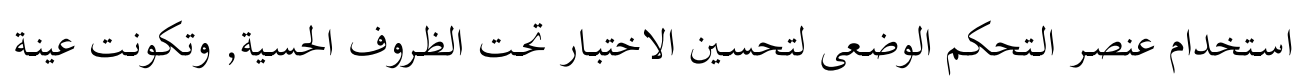

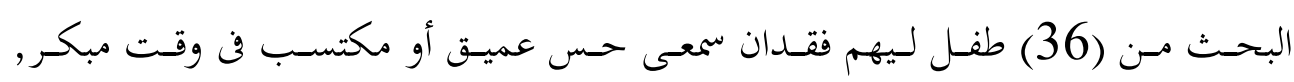

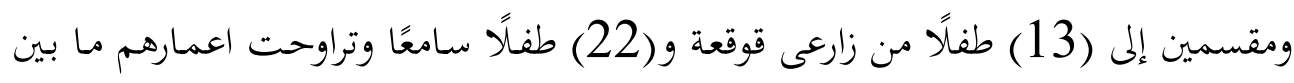

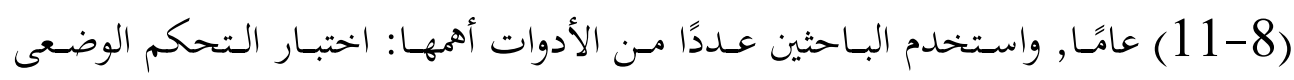

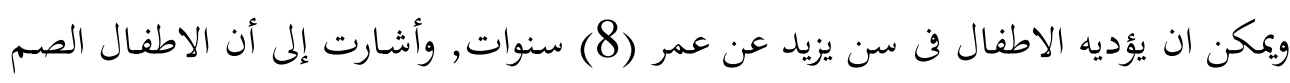

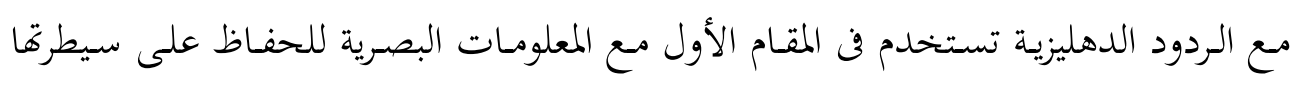

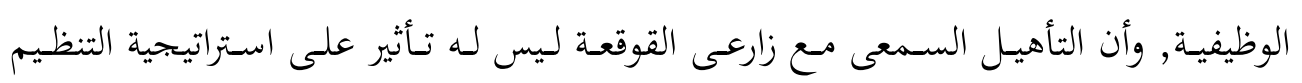

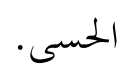
كما استهافت دراسة (2009) Bharadwaj, et.al, على التعرف على اضطراب المعالجة الحسية لأطفال زارعى القوقعة والكشف عن العلاقة بين اضطراب المعالجة الحسية على التطراب 
ومـدة فقدان السمع ووقت زرع القوقعة, وتكونت عينة البحثث مـن (30) طفل تراوحت

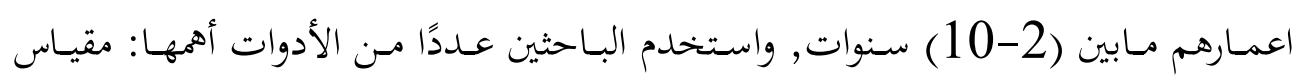

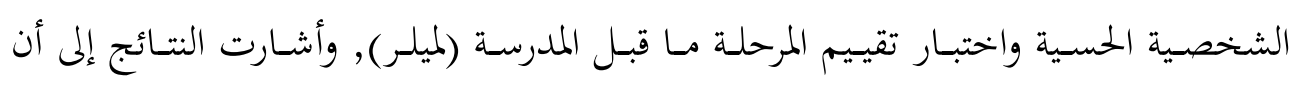

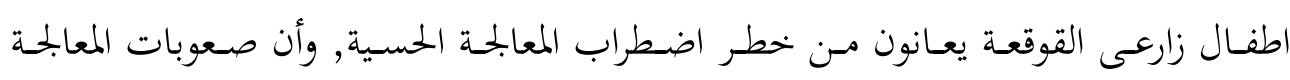

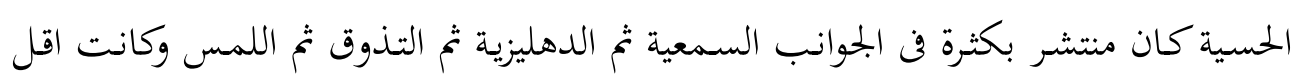

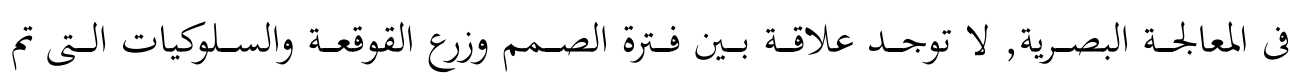
تحديدها.

وقد استهدفت دراسة (2012) مharadwaj, et.al, التحقق من وظائف

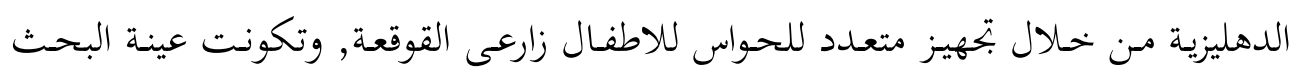

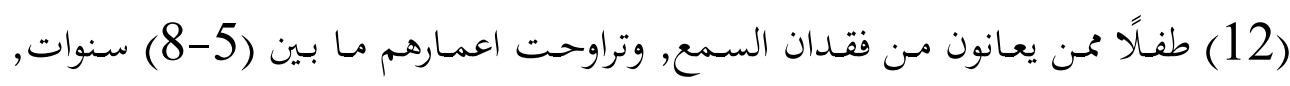

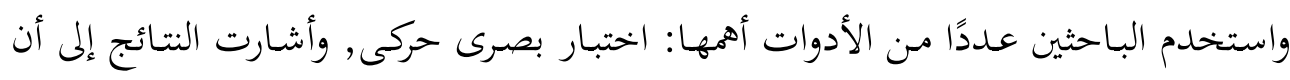

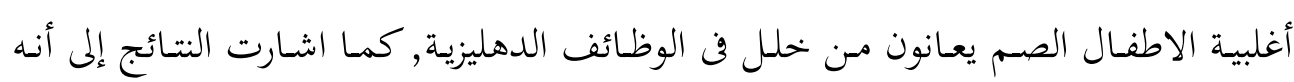
يمكن تحفيز اللمس والبصر لدى الاطفال زارعى القوقعة عن طريق التكامل الحسى.

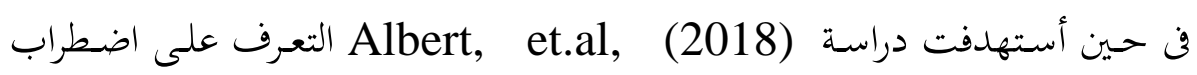

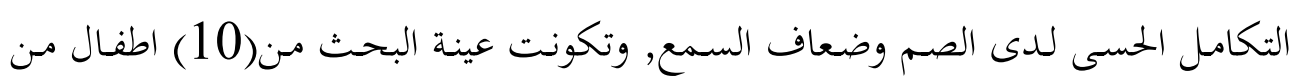

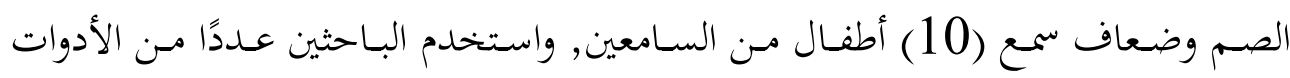

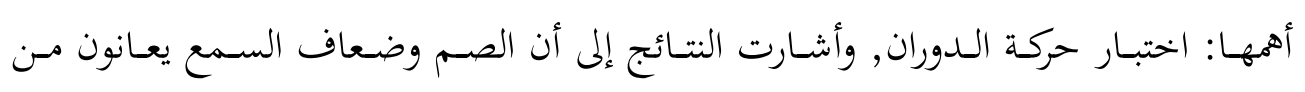
اضطراب فن التوجه المكانى وصعوبات في الحفاظ على التوازن الحركى في الظلام.

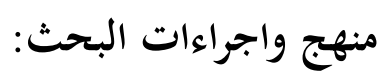

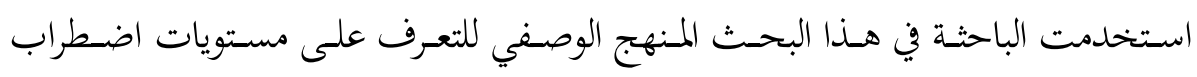

$$
\text { التكامل الحسى لدى الصم وضعاف السمع. }
$$

تكونت عينة البحثث مـن (100) تلميذًا مـن التلاميذ الصـم وضعاف السمع, وتتراوح

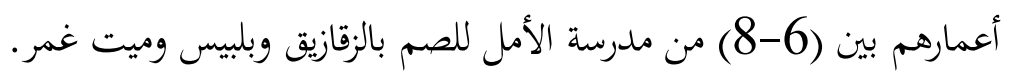




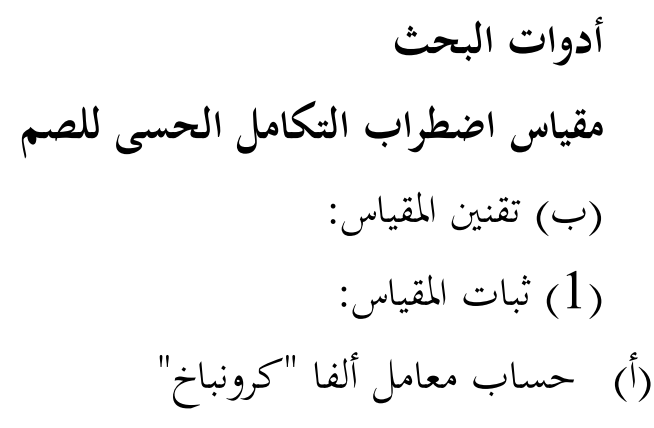

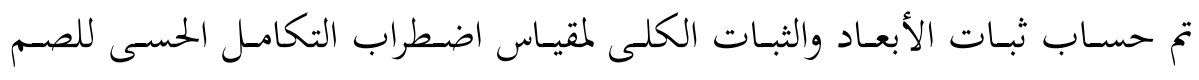

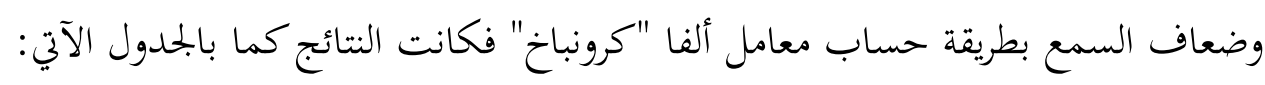

جدول (1)

معاملات الفاكرونباخ لأبعاد مقياس اضطراب التكامل الحسى للصم وضعاف (1)

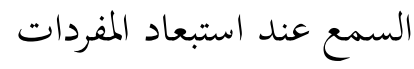

\begin{tabular}{|c|c|c|c|c|c|c|c|c|c|c|c|c|c|c|c|c|c|}
\hline \multicolumn{2}{|c|}{$\begin{array}{c}\text { البعد السابع } \\
\text { الفاكرونباخ = } \\
\text { 5 570, }\end{array}$} & \multicolumn{2}{|c|}{$\begin{array}{c}\text { البعد السادس } \\
\text { الفاكرونباخ } \\
\text { 6عامل } \\
\text { 609 }\end{array}$} & \multicolumn{3}{|c|}{ 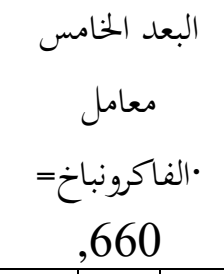 } & \multicolumn{3}{|c|}{$\begin{array}{c}\text { البعد الرابع } \\
\text { الفاكرونباخ = } \\
\text { 7عامل } \\
\text { 709 }\end{array}$} & \multicolumn{2}{|c|}{ 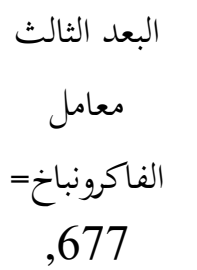 } & \multicolumn{3}{|c|}{$\begin{array}{c}\text { البعد الثاكانان } \\
\text { الفرونباخ= } \\
\text { 808 } \\
\text { 808 }\end{array}$} & \multicolumn{3}{|c|}{ 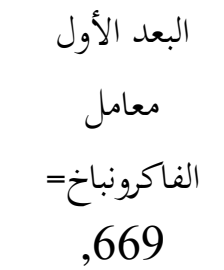 } \\
\hline $\begin{array}{l}5 \\
7 \\
, 0\end{array}$ & 7 & $\begin{array}{l}5 \\
7 \\
, 4\end{array}$ & 6 & تبع & \begin{tabular}{|l|}
6 \\
7 \\
\end{tabular} & 5 & تس & $\begin{array}{l}7 \\
3 \\
9\end{array}$ & 4 & \begin{tabular}{l|}
6 \\
7 \\
4
\end{tabular} & 3 & تس & $\begin{array}{l}8 \\
1 \\
9\end{array}$ & 2 & & $\begin{array}{l}6 \\
6 \\
, 3\end{array}$ & 1 \\
\hline $\begin{array}{l}5 \\
6 \\
, 0\end{array}$ & $\begin{array}{l}1 \\
4\end{array}$ & $\begin{array}{l}6 \\
0 \\
, 0\end{array}$ & $\begin{array}{l}1 \\
3\end{array}$ & & $\begin{array}{c}6 \\
1 \\
, 1\end{array}$ & $\begin{array}{l}1 \\
2\end{array}$ & & $\begin{array}{l}7 \\
0 \\
7\end{array}$ & $\begin{array}{l}1 \\
1\end{array}$ & $\begin{array}{l}6 \\
4 \\
, 6\end{array}$ & $\begin{array}{l}1 \\
0\end{array}$ & & $\begin{array}{l}8 \\
0 \\
1\end{array}$ & 9 & تبع & $\begin{array}{l}6 \\
9 \\
, 5\end{array}$ & 8 \\
\hline $\begin{array}{l}5 \\
0 \\
, 0\end{array}$ & $\begin{array}{l}2 \\
1\end{array}$ & $\begin{array}{l}5 \\
8 \\
, 9\end{array}$ & $\begin{array}{l}2 \\
0\end{array}$ & & $\begin{array}{c}6 \\
6 \\
, 0\end{array}$ & $\begin{array}{l}1 \\
9\end{array}$ & & $\begin{array}{c}6 \\
8 \\
8\end{array}$ & 8 & $\begin{array}{l}6 \\
0 \\
6\end{array}$ & $\begin{array}{l}1 \\
7\end{array}$ & & $\begin{array}{l}8 \\
0 \\
0\end{array}$ & $\begin{array}{l}1 \\
6\end{array}$ & & $\begin{array}{l}6 \\
6 \\
, 3\end{array}$ & $\begin{array}{l}1 \\
5\end{array}$ \\
\hline $\begin{array}{l}5 \\
1 \\
, 2\end{array}$ & $\begin{array}{l}2 \\
8\end{array}$ & $\begin{array}{l}6 \\
0 \\
, 0\end{array}$ & $\begin{array}{l}2 \\
7\end{array}$ & & \begin{tabular}{|l|}
6 \\
4 \\
, 8
\end{tabular} & $\begin{array}{l}2 \\
6\end{array}$ & & $\begin{array}{l}6 \\
6 \\
, 7\end{array}$ & 5 & $\begin{array}{l}6 \\
6 \\
2\end{array}$ & $\begin{array}{l}2 \\
4\end{array}$ & & $\begin{array}{l}7 \\
0 \\
4\end{array}$ & $\begin{array}{l}2 \\
3\end{array}$ & تبع & $\begin{array}{l}6 \\
9 \\
, 7\end{array}$ & $\begin{array}{l}2 \\
2\end{array}$ \\
\hline
\end{tabular}




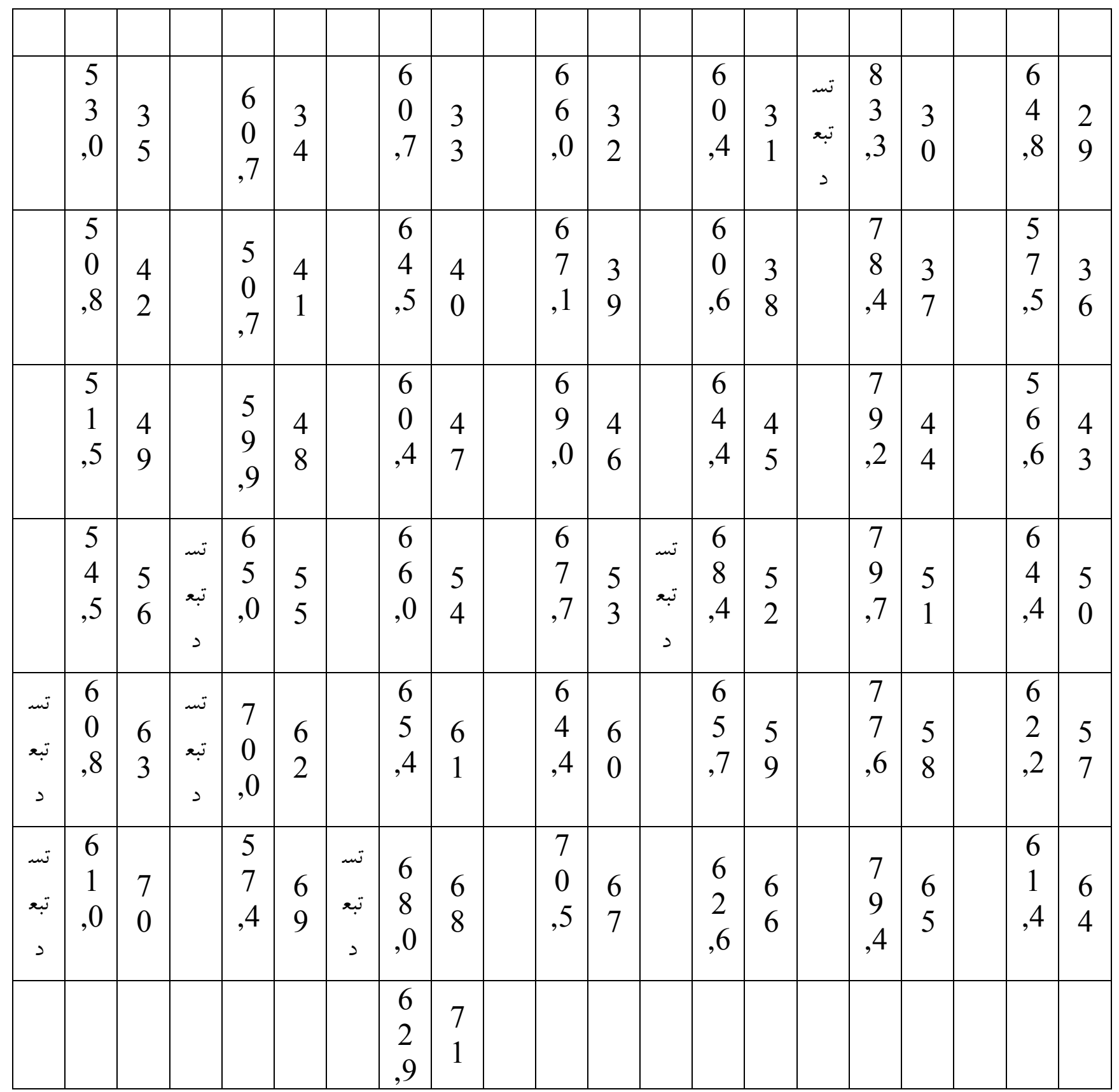

يتضح من جدول (1) أن معاملات ثبات أبعاد المقياس مرتفعة حيث تراوحت بين

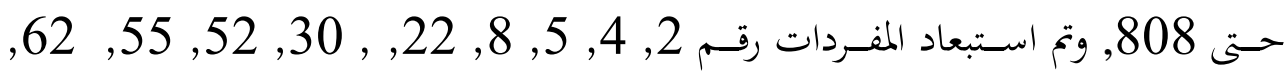
63, 68, 70 ومن ثم يمكن أن نثق في نتائجه. 
جدول (2) معامل الارتباط بين درجتى أبعاد الأم والمعلمة لمقياس اضطراب التكامل

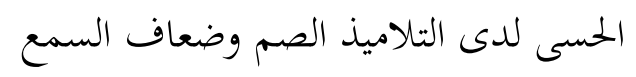

\begin{tabular}{|c|c|c|c|c|c|c|c|c|}
\hline الدرجة الكلي & البابع & البعد السادس & البعد الخامس & البعد الرابع & البعد الثالث & البعد الثانى & البعد الأول & \\
\hline *** ,285 & ${ }^{*}, 222$ & , 186 & * 235 & ***, 327 &, 041 & , 191 & ** ,498 & البعد الأول \\
\hline *** ,506 & *** 310 & , 152 & ***,230 & ***, 416 & ***,301 & ***, 646 & , 160 & البعد الثان \\
\hline *** ,590 & ** ,392 & *, 237 & ***,396 & ***, 386 & ***, 640 & ***, 284 & *, 251 & البعد الثالث \\
\hline ***, 557 & ***, 399 &, 110 & ***,411 & ***, 672 & * 236 & ***, 306 & * 209 & البعد الرابع \\
\hline ***, 520 & ***, 344 & ***, 224 & ***,493 & ***, 495 & *,207 & * ,206 & ***, 259 & البعد الخامس \\
\hline ***, 386 & , 101 & *** ,710 & ,156 & ,090 & ***,283 & ***, 311 & ,003- & البعد السادس \\
\hline ***,398 & ***,552 & ,38 & *,229 & $*, 200$ & $*, 227$ & ***, 229 & ***, 273 & البعد السابع \\
\hline **, 763 & ***, 507 & ***, 412 & ***,487 & ***, 588 & ***,445 & ***, 529 & ***,345 & الدرجة الكلية \\
\hline
\end{tabular}

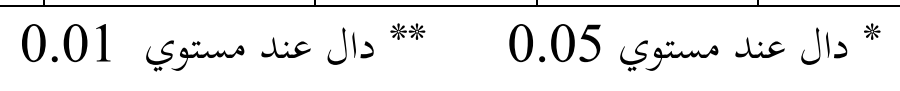

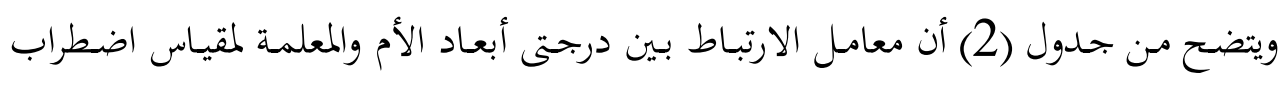

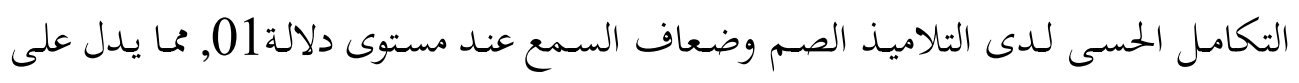
صدق المقياس.

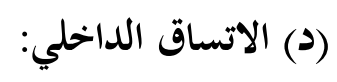

تم حساب الاتساق الداخلي لمفردات المقياس من خحلال حساب معامل الارتباط بين

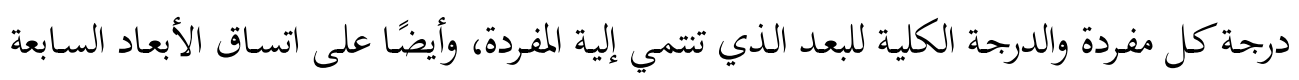

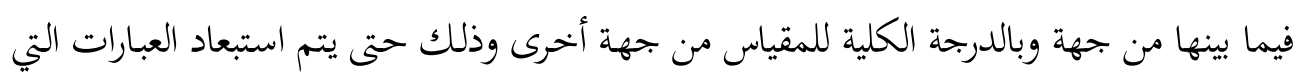

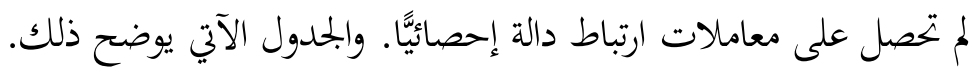

$$
\text { جدول(3) }
$$

\begin{tabular}{|c|c|c|c|c|c|c|}
\hline البعد الساعي & 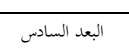 & البعدا الخاس & 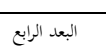 & 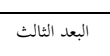 & 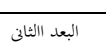 & البعا الأرل \\
\hline
\end{tabular}

معاملات الارتباط بين كل مفردة والدرجة الكلية للبعد الذي تنتمي إليه 


\begin{tabular}{|c|c|c|c|c|c|c|c|c|c|c|c|c|c|c|c|c|c|c|c|c|}
\hline $\begin{array}{l}\sum_{\Sigma} \\
\xi \\
6 \\
\xi \\
\xi\end{array}$ & 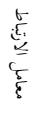 & 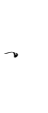 & $\begin{array}{l}\frac{\xi}{2} \\
\xi \\
\sigma \\
\xi \\
\xi\end{array}$ & 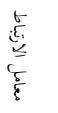 & $\checkmark$ & 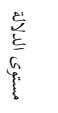 & 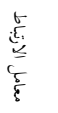 & $\checkmark$ & 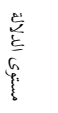 & 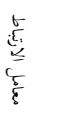 & $\checkmark$ & $\begin{array}{l}\stackrel{\xi}{\zeta} \\
\xi \\
G \\
\xi \\
\xi\end{array}$ & 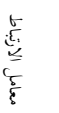 & $\checkmark$ & 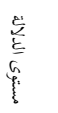 & 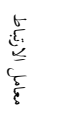 & $\rightarrow$ & 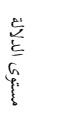 & 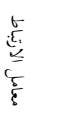 & $\curvearrowright$ \\
\hline ,01 &, 70 & 7 & ,01 & ,54 & 6 & غير دالة & ,09 & 5 & غالة & ,03 & 4 & ,01 & ,37 & 3 & غير دالة & ,07 & 2 & غير دالة & ,24 & 1 \\
\hline ,01 &, 45 & 14 & ,01 & ,60 & 13 & ,01 &, 37 & 12 & غير & ,24 & 11 & ,01 & ,54 & 10 & ,01 & ,39 & 9 & غير دالة & ,06 & 8 \\
\hline ,01 &, 54 & 21 & ,01 & ,58 & 20 & ,01 & ,45 & 19 & ,01 & ,36 & 18 & 01 & ,59 & 17 & ,01 & ,40 & 16 & ,05 & ,32 & 15 \\
\hline ,01 &, 5 & 28 & 01 & ,68 & 27 & ,01 & ,38 & 26 & ,01 & ,50 & 25 & ,01 & ,65 & 24 & ,01 & ,58 & 23 & غير دالة & ,06 & 22 \\
\hline غير & ,008 & 35 & ,01 & ,70 & 34 & ,01 & ,59 & 33 & ,01 & ,50 & 32 & غير & ,23 & 31 & غالة & ,20 & 30 & ,01 & ,62 & 29 \\
\hline ,01 & ,50 & 42 & ,01 & ,50 & 41 & ,01 & ,48 & 40 & ,01 & ,46 & 39 & ,01 & $\begin{array}{l}, 38 \\
\end{array}$ & 38 & ,01 & ,62 & 37 & ,01 & ,65 & 36 \\
\hline ,01 &, 51 & 49 & ,05 & ,32 & 48 & ,01 & ,47 & 47 & ,01 & ,43 & 46 & ,05 & ,32 & 45 & ,01 & ,51 & 44 & ,01 & ,50 & 43 \\
\hline ,05 & ,32 & 56 & دالة & ,005 & 55 & ,01 & ,60 & 54 & ,05 & ,35 & 53 & داله & ,006 & 52 & ,01 & ,55 & 51 & ,01 & ,45 & 50 \\
\hline دالة &, 12 & 63 & دالة & ,23 & 62 & ,01 & ,69 & 61 & ,01 & ,63 & 60 & ,01 & ,65 & 59 & ,01 & ,64 & 58 & ,05 & ,34 & 57 \\
\hline \multirow[t]{2}{*}{ دالة } & , 10 & 70 & ,01 & ,57 & 69 & غير & ,008 & 68 & ,01 & ,49 & 67 & ,01 & ,47 & 66 & ,01 & ,46 & 65 & ,01 & ,47 & 64 \\
\hline & & & & & & ,01 & ,69 & 71 & & & & & & & & & & & & \\
\hline
\end{tabular}

بالنظر إلى جدول (3) بند معظم العبارات كانت دالة إحصائيَّا عند مستوى (0,01)،

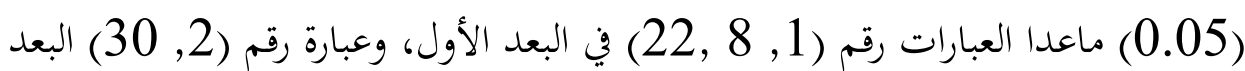

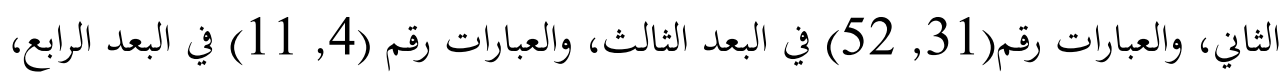

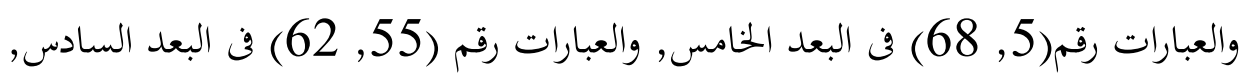

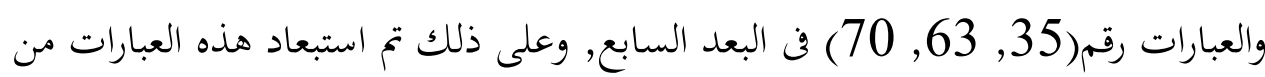
الصورة النهائية للمقياس. ويتكون المقياس في صورته النهائية من (55) عبارة موزعة كما في الجحدول الآين: جدول (4) (د) (د) مفتاح تصحيح مقياس اضطراب التكامل الحسى لدى الصم وضعاف السمع (4)

\begin{tabular}{|c|c|c|}
\hline العبارات & أرقام العبارات & أبعاد المقياس \\
\hline 7 & 1 $8,15,22,29,36,43,46$ & حاسة السمع \\
\hline 8 & 2, 9, 16, 23, 30, 37, 44, 50 & الحاسة الدهليزية \\
\hline
\end{tabular}




\begin{tabular}{|c|c|c|}
\hline 8 & $51,45,38,31,24,17,10,3$ & 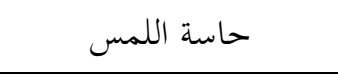 \\
\hline 8 & $52,46,39,32,25,18,11,4$ & حاسة الحس حركى العميق \\
\hline 9 & $\begin{array}{c}53,47,40,33,26,19,12,5 \\
55\end{array}$ & حاسة البصر \\
\hline 8 & 6 $54,48,41,34,27,20,13,4,4$ & 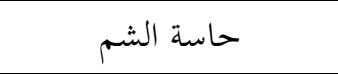 \\
\hline 7 & 7, 14, 21, , 28, 35, 42, 49 & حاسة التذوق \\
\hline 55 & موع الكلى & \\
\hline
\end{tabular}

مـ الإجراءات السابقة تأكدات الباحثة من ثبات وصدق مقياس اضطراب التكامل

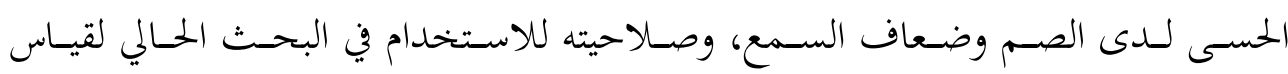

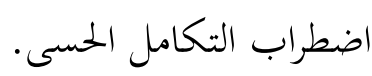

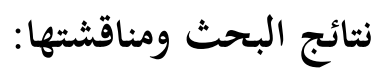 \\ نتائج اختبار صحة السؤال الأول:}

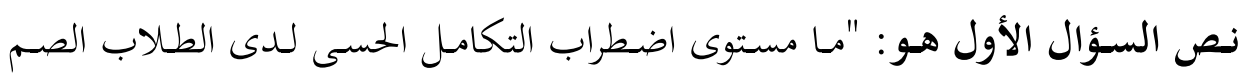

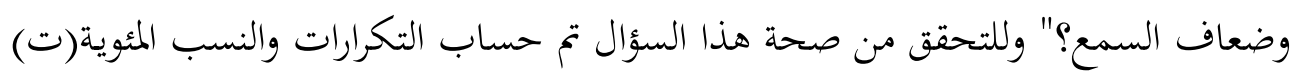

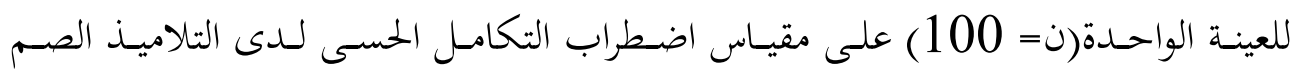
وضعاف السمع على النحو الذي يوضحه الجدول رقم(5): جدول (5)

\begin{tabular}{|c|c|c|c|c|c|c|}
\hline مستوى الدلالة & قيمة ت & المتوسط & الانمراف & المتتوسطى & العدد & البعد \\
\hline ,01 & 3,120 & 106,46 & 11,35 & 110 & 100 & اضطراب التكامل \\
\hline
\end{tabular}

يتضح من الجحدول (5) أن التلاميذ الصم وضعاف السمع لديهم اضطراب التكامل الحسى حيث أن المتوسط الحقيقى أكبر من المتوسط العام. 


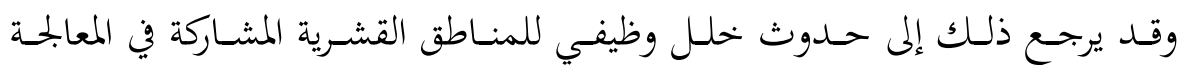

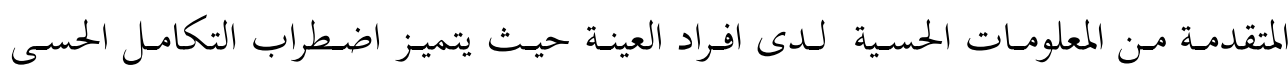

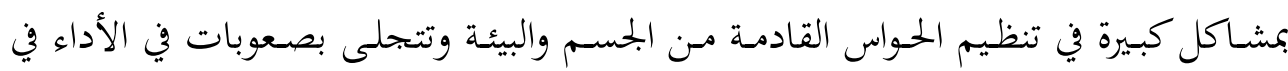

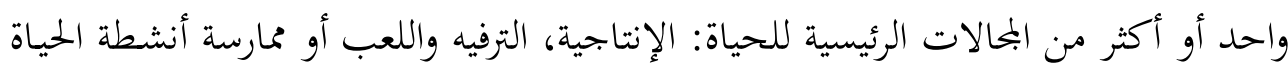

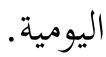

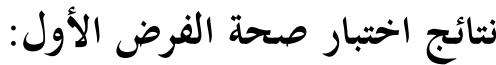

ينص الفرض الأول على أنه "تُعد حاسة الدهليزية هى الاول: أكثر الحواس اضطرابا لدى الدى

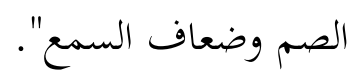

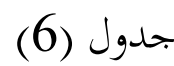

ترتيب أبعاد اضطراب التكامل الحسى لدى الصم وضعاف السمع(ن=100)

\begin{tabular}{|c|c|c|c|c|c|}
\hline الترتيب & فروق & المتوسط & المتوسط للبعد & علمفد & أبعاد \\
\hline 3 &, 05 & 14,05 & 14 & 7 & حاسة السمع \\
\hline 1 & ,36 & 16,36 & 16 & 8 & حاسة الدهليزية \\
\hline 6 & ,68- & 15,32 & 16 & 8 & حاسة اللمس \\
\hline 2 &, 25 & 16,25 & 16 & 8 & حركى العميق الحس \\
\hline 7 & $1,46-$ & 16,54 & 18 & 9 & حاسة البصر \\
\hline 5 & ,66- & 15,34 & 16 & 8 & حاسة الشم \\
\hline 4 & ,4- & 13,60 & 14 & 7 & حاسة التذوق \\
\hline
\end{tabular}

يتضح من جدول (6) ما يأتي: أن الأطفال الصم وضعاف السمع اظهروا اضطراب

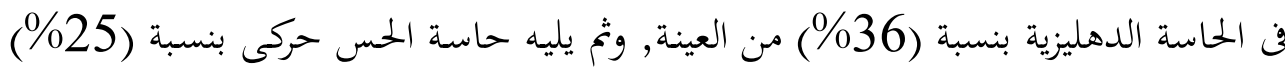

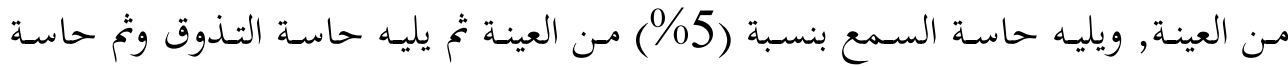
الشم وثم حاسة اللمس ثم حاسة البصر. 
أن أكثر أبعاد مقياس اضطراب التكامل الحسى شيوعًا هو حاسة التنظيم الدهليزى

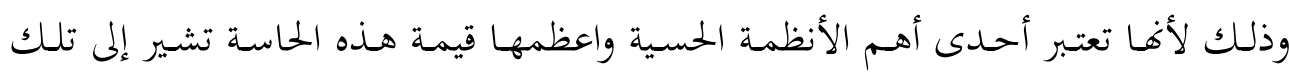

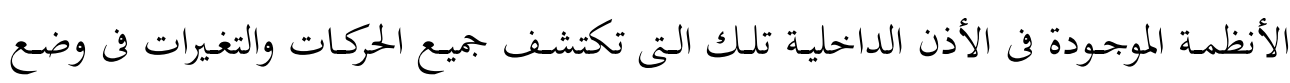

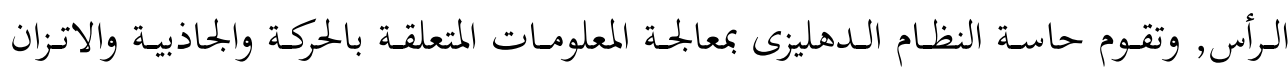

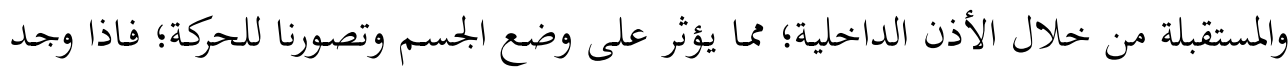

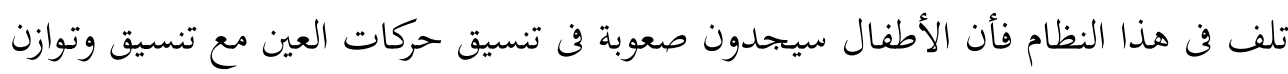

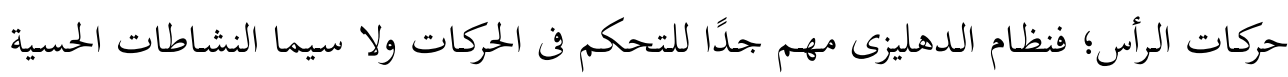

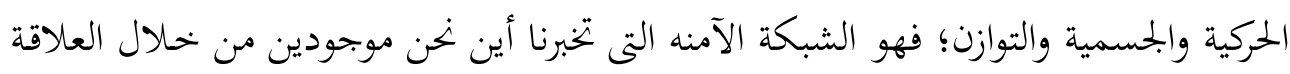
مع الفضاء أو الحيز الذى ينوى الفرد التحرك أو الأبخذاب إليه.

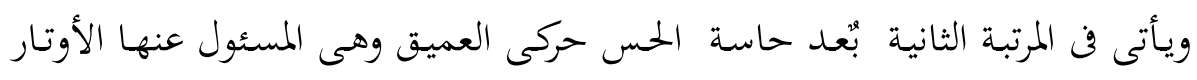

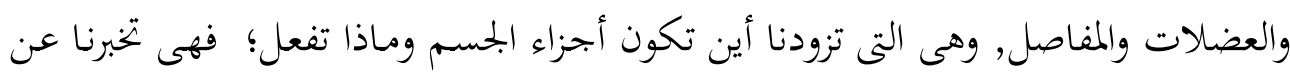

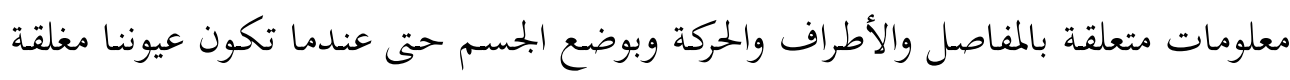

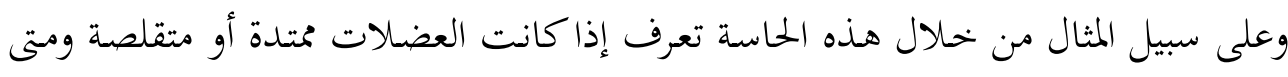

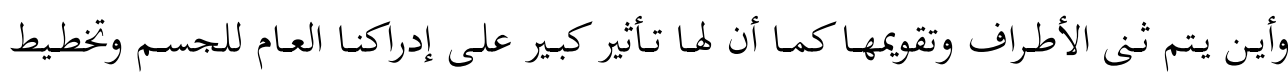

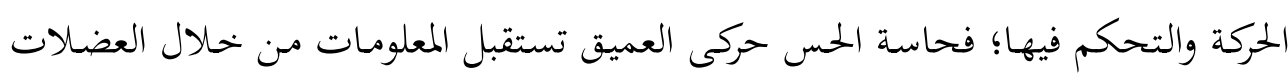

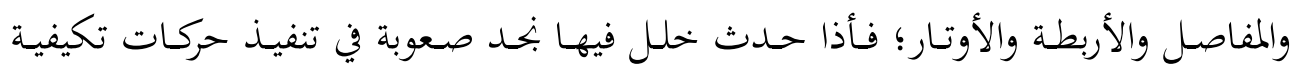
بسيطة مثل الجلوس والوقوف, وصعوبة فهم واستخدام مكونات البيئة المخيطة, وتأخر الإدراك

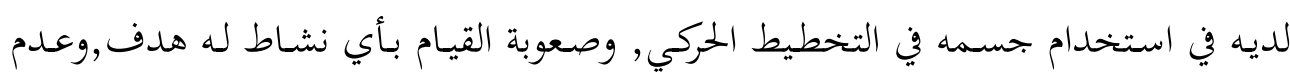

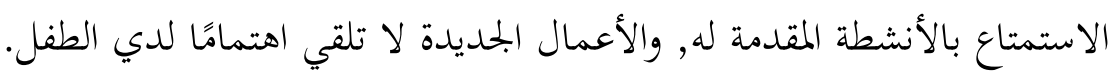

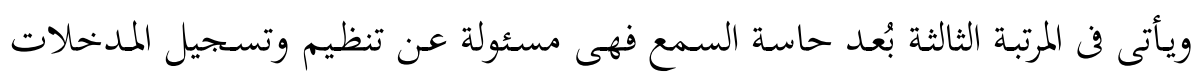

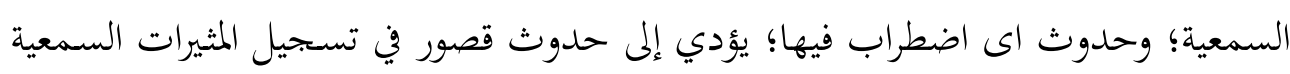

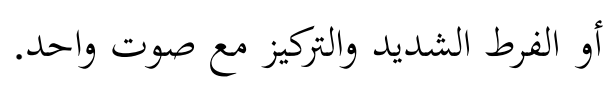

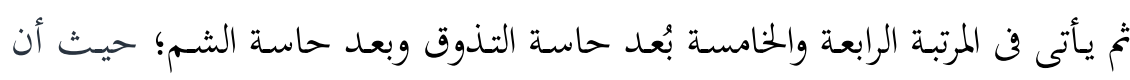

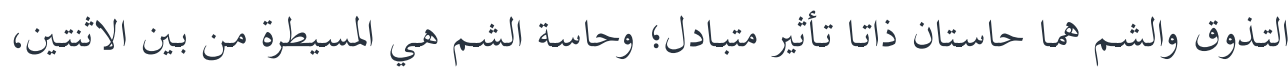

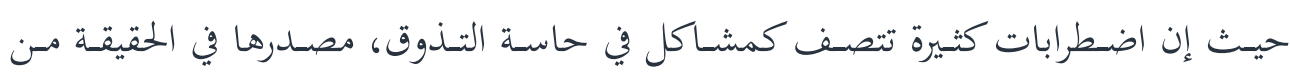


اضطراب في حاسة الشم؛ حيث أن الأطفال يعانوا مـن صعوبة في التغذية ويتناولوا أطعمة محددة.

ويأتى في المرتبة السادسة بُعد حاسة اللمس حيث تتضمن الخلايا الحسية الموجودة تحت

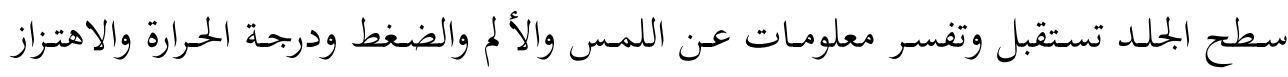
والحركة؛ حيث تؤدى هذه المعلومات دور مهم فن إدراك البيئة, واستقرارنا العاطفى, وتئثرث

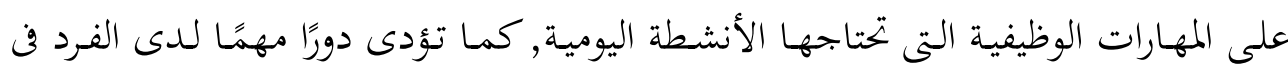
الوعى بالجسم وتركيز الانتباه.

وتأتى فن المرتبة السابعه بُعد حاسة البصر تتمثل العيوب البصرية بين الأفراد الصم

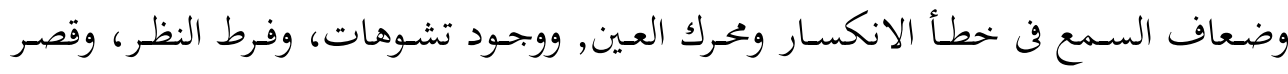

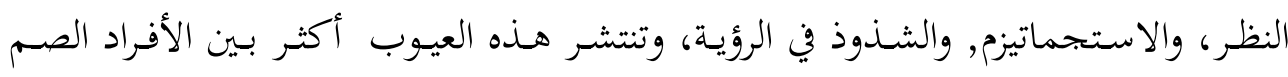

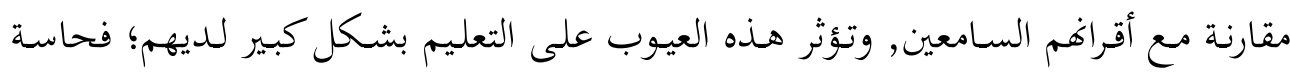

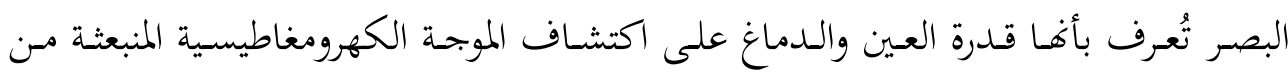

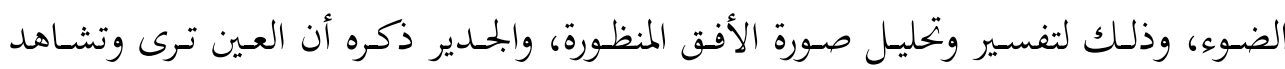

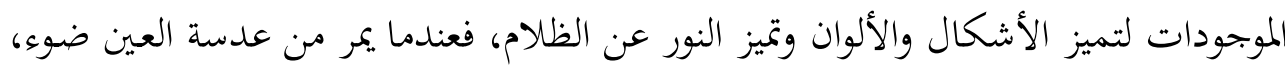

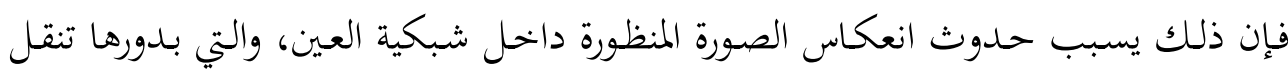

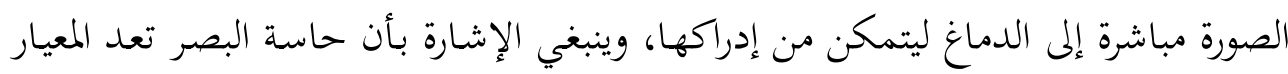
بين قدرة الإنسان على الرؤية والعمى.

\section{نتائج اختبار صحة الفرض الثانى:}

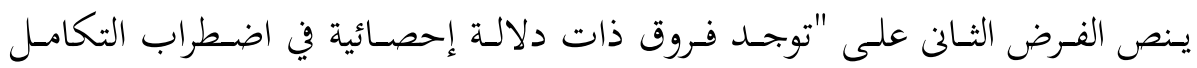
الحسى لدى التلاميذ الصم وضعاف السمع لصالح التلاميذ الصم".

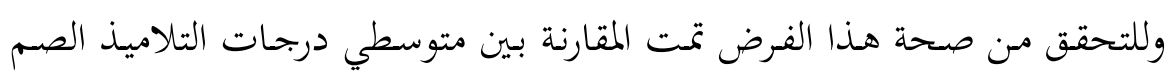

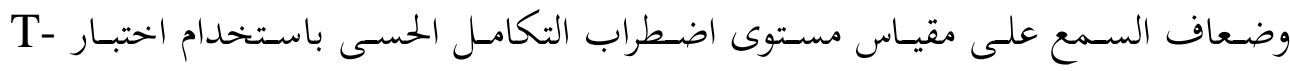
Test جدول (7) 
المقارنة بين متوسطي درجات التلاميذ الصم وضعاف السمع على مقياس اضطراب

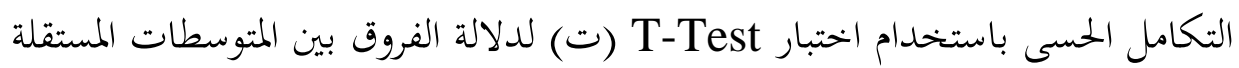

\begin{tabular}{|c|c|c|c|c|c|c|}
\hline \multirow{2}{*}{ ل دلالتها } & \multirow{2}{*}{ ق ق قيمة ت } & \multicolumn{2}{|c|}{ ضعاف السمع ن = 35} & \multicolumn{2}{|c|}{ الصم ن =65 } & \multirow{2}{*}{ أبعاد الإنحاز الأكاديمي } \\
\hline & & $\varepsilon$ & م & $\varepsilon$ & r & \\
\hline غير دالة & $\begin{array}{c}- \\
0,37\end{array}$ & 2,06 & 14,17 & 2,54 & 13,98 & حاسة السمع \\
\hline غير دالة & ,73- & 2,54 & 16,11 & 2,38 & 16,49 & الحاسة الدهليزية \\
\hline غير دالة & ,29- & 2,51 & 15,42 & 2,86 & 15,62 & حاسة اللمس \\
\hline غير دالة & $\begin{array}{c}- \\
1,69\end{array}$ & 2,54 & 15,91 & 3,04 & 14,89 & حاسة الحس حركى \\
\hline غير دالة & $\begin{array}{c}- \\
1,24\end{array}$ & 2,40 & 17,02 & 3,10 & 16,27 & حاسة البصر \\
\hline غير دالة & ,16- & 2,58 & 15,40 & 2,97 & 15,30 & حاسة الشم \\
\hline غير دالة & $\begin{array}{c}- \\
3,87\end{array}$ & 1,83 & 13,48 & 2,32 & 13,66 & حاسة التذوق \\
\hline غير دالة & ,69- & 10,19 & 107,54 & 11,95 & 105,87 & الدرجة الكلية \\
\hline
\end{tabular}

يتضح من الجدول(7 ) ما يأتي:

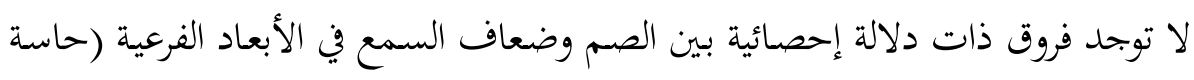

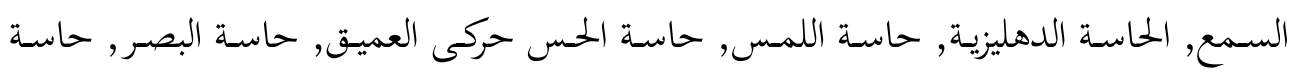

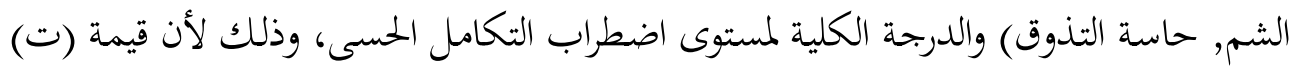

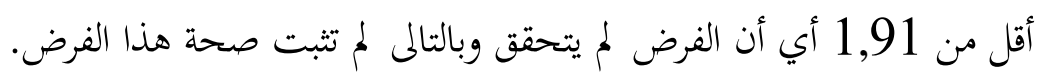

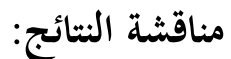

ويمكن تفسير عـدم وجـود فروق ذات دلالة إحصائية بـين الصـم وضسعاف السـمع في

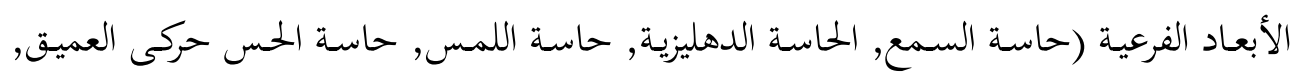

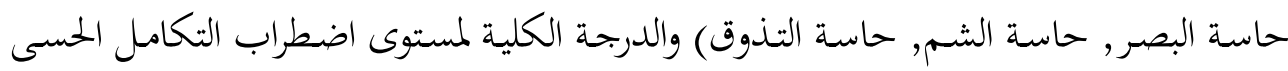

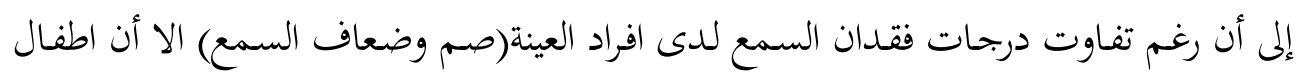


اضطراب التكامل الحسى يعانون من شىء واحد في الجمل وهو الاختلالات الوظيفية في تكامل

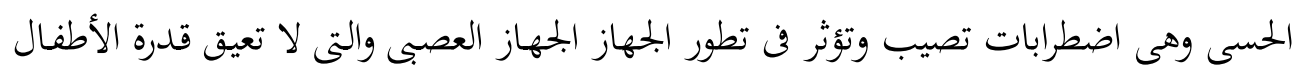

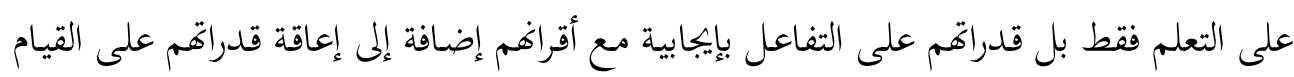

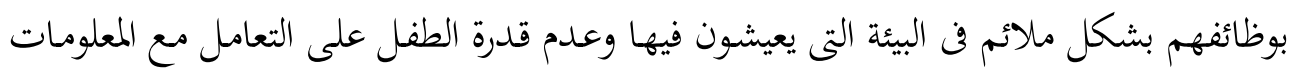

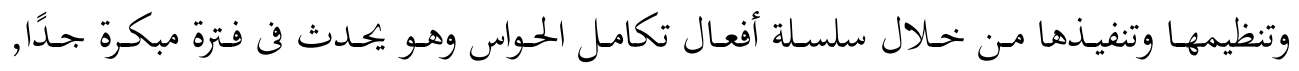

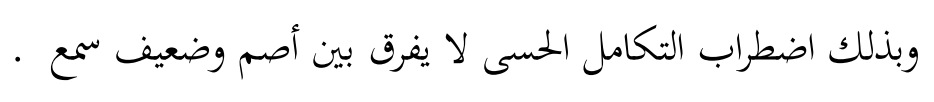

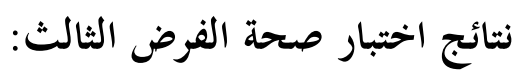

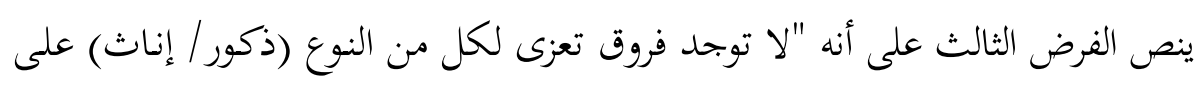

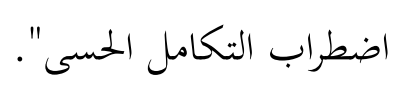

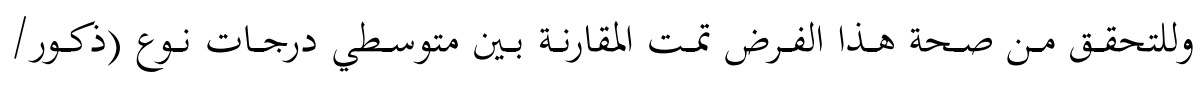

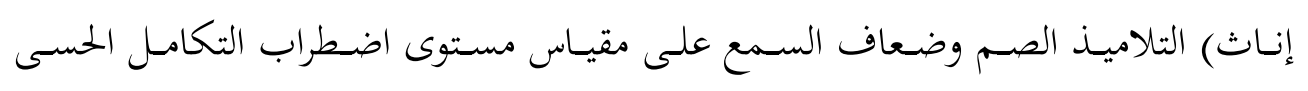

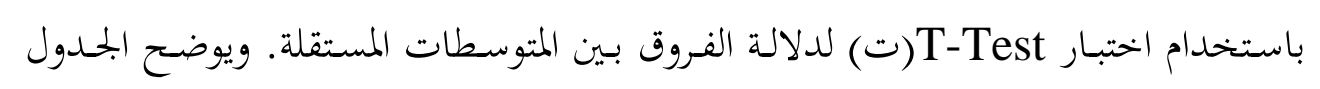
الآتي نتائج ذلك.

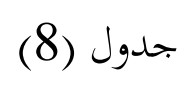

المقارنة بين متوسطي درجات التلاميذ الذكور والاناث على مقياس اضطراب التكامل

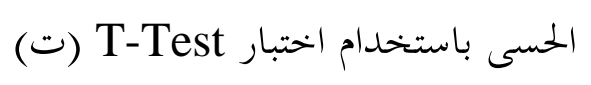

\begin{tabular}{|c|c|c|c|c|c|c|}
\hline \multirow{2}{*}{ حلالتها } & \multirow{2}{*}{ قيمة } & \multicolumn{2}{|c|}{ اناث = 39} & \multicolumn{2}{|c|}{ كور ن = } & \multirow{2}{*}{ أبعاد الإنحاز الأكاديكي } \\
\hline & & $\varepsilon$ & r & $\varepsilon$ & r & \\
\hline ر ردالة & $\begin{array}{c}- \\
1,56\end{array}$ & 2,50 & 14,51 & 2,26 & 13,75 & حاسة السمع \\
\hline 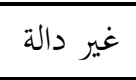 & ,75- & 1,8 & 16,58 & 2,67 & 160 & \\
\hline 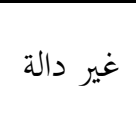 & $\begin{array}{c}- \\
1,23\end{array}$ & 2,67 & 14,89 & 2,67 & 15,59 & حاسة اللمس \\
\hline غير دالة ل غل & ,68- & 3,20 & 15,00 & 2,72 & 15,40 & ة المس حركى العميق \\
\hline
\end{tabular}

لد لالة الفروق بين المتوسطات المستقلة 


\begin{tabular}{|c|c|c|c|c|c|c|}
\hline \multirow{2}{*}{ دلالتها } & \multirow{2}{*}{ تيمة } & \multicolumn{2}{|c|}{ اناث = 39} & \multicolumn{2}{|c|}{ ذكور ن = 61} & \multirow{2}{*}{ أبعاد الإنحاز الأكاديمي } \\
\hline & & $\varepsilon$ & p & $\varepsilon$ & p & \\
\hline غير دالة & ,99- & 2,75 & 16,17 & 2,29 & 16,77 & حاسة البصر \\
\hline غير دالة & ,05- & 2,52 & 15,35 & 2,83 & 15,32 & حاسة الشم \\
\hline غير دالة & ,15- & 2,73 & 13,64 & 2,02 & 13,57 & حاسة التذوق \\
\hline غير دالة & ,19- & 11,77 & 106,17 & 11,16 & 106,63 & الدرجة الكلية \\
\hline
\end{tabular}

يتضح من الجحدول(8 ) أنه لا توجد فروق ذات دلالة إحصائية بين الذكور والاناث في

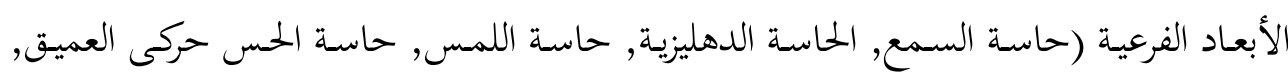

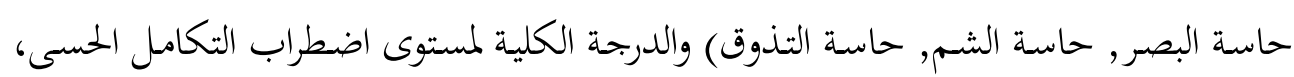

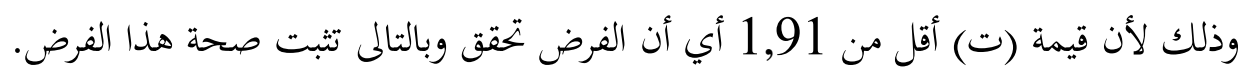

\section{مناقشة النتائج:}

تتفق تلك النتيجة " لا توجد فروق تعزى لكل من النوع (ذكور / إناث) مع نتائج

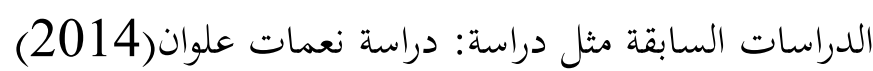

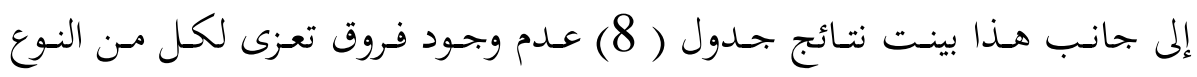

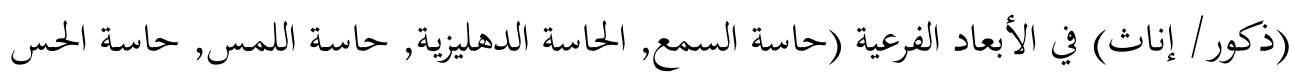

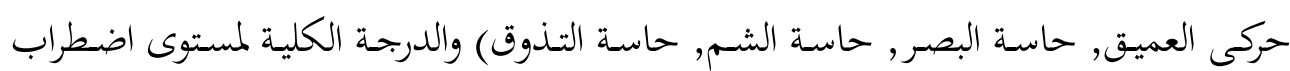

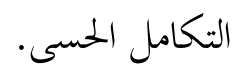

ويبدأ التكامل الحسى فن الرحم حيث تتطور هذه الحواس الخفية بشكل مبكر في

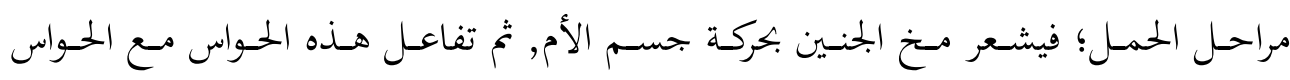

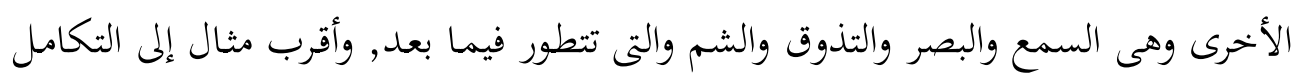

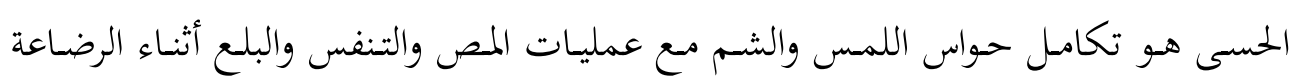

الطبيعية للطفل الرضيع(Ayres, 2005, p. 15).

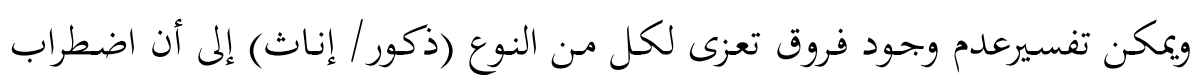

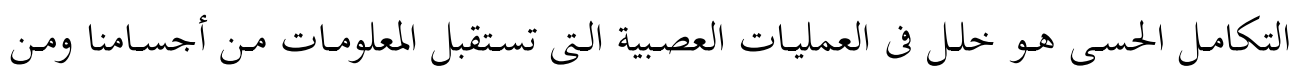

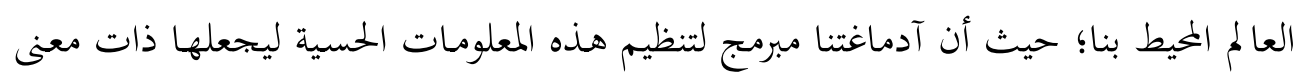


لنا وأى خلل فن العملية العصبية البيولوجية الداخلية يؤدى إلى خلل فن التفاعل والتداخل

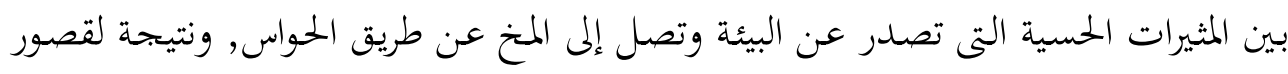

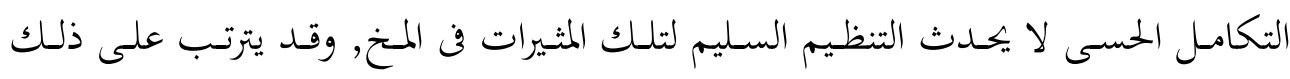

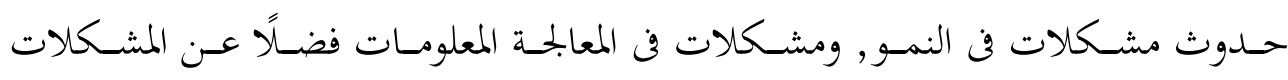

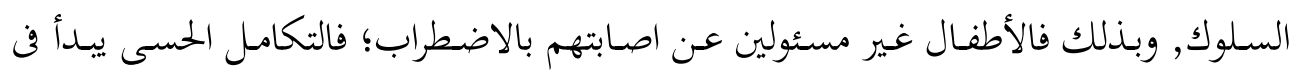

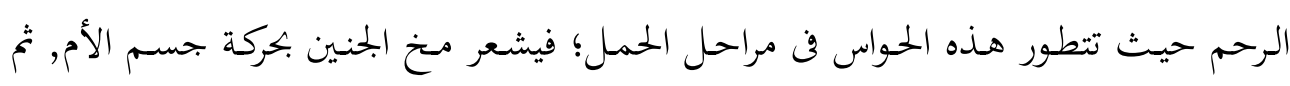

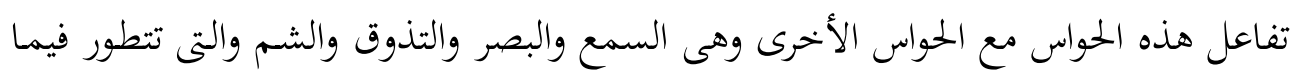

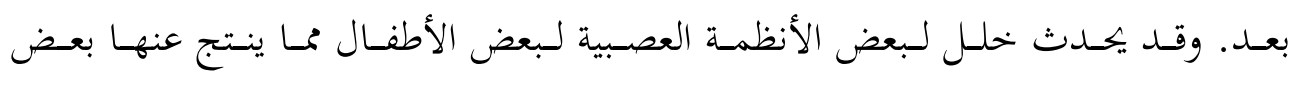

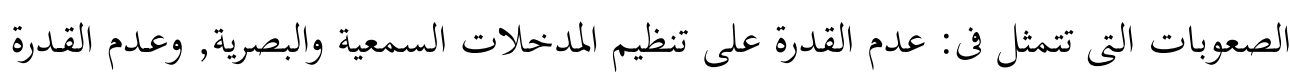

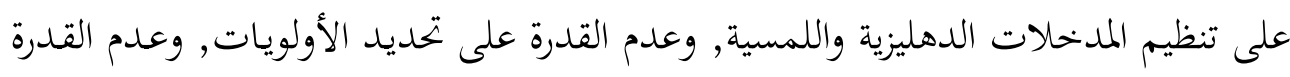

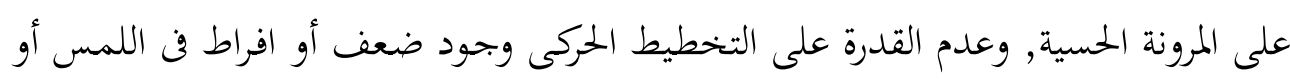

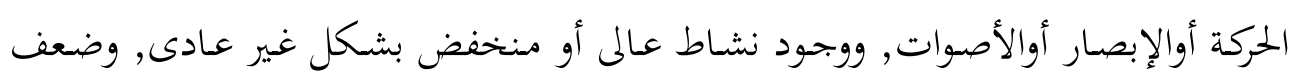

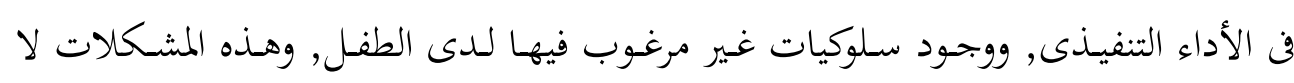
تفرق بين ذكر واننى فن الأطفال.

\section{نتائج اختبار صحة الفرض الرابع:}

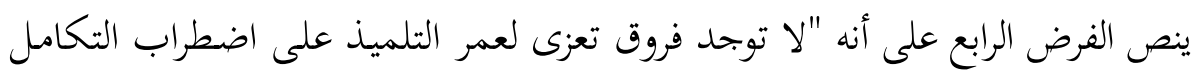

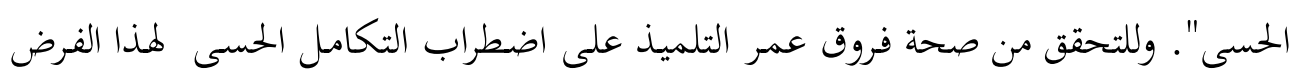
استخدمت الباحثة تحليل التباين أحادي الاتحاه، وتلخيص النتائج في الجحدولين الآتيين.

$$
\text { جدول (9) }
$$

\begin{tabular}{|c|c|c|c|c|}
\hline الانحراف المعياري & المتوسط & العدد & السن & الأبعاد \\
\hline 228035 & 1400 & 21 & 6 سنوات & \multirow{4}{*}{ حاسة السمع } \\
\hline 2,41994 & 14,51 & 41 & 7 سنوات & \\
\hline 2,29307 & 14,65 & 38 & 8سنهات & \\
\hline 2,37570 & 14,05 & 100 & اجمالم & \\
\hline
\end{tabular}




\begin{tabular}{|c|c|c|c|c|}
\hline الانحراف المعياري & المتوسط & العدد & السن & الأبعاد \\
\hline $\begin{array}{l}2,12804 \\
2,69462 \\
2,32128 \\
2,43510\end{array}$ & $\begin{array}{l}16,08 \\
16,19 \\
16,26 \\
16,36\end{array}$ & $\begin{array}{c}21 \\
41 \\
38 \\
100\end{array}$ & 6 8 6 سنوات & الحاسة الدهليزية \\
\hline $\begin{array}{l}2,46209 \\
2,63460 \\
2,79466 \\
2,73625\end{array}$ & $\begin{array}{l}14,47 \\
15,14 \\
15,97 \\
15,32\end{array}$ & $\begin{array}{c}21 \\
41 \\
38 \\
100\end{array}$ & 6 8 6 سنوات & حاسة اللمس \\
\hline $\begin{array}{l}2,59762 \\
3,31331 \\
2,56300 \\
2,91071\end{array}$ & $\begin{array}{l}14,95 \\
14,85 \\
15,84 \\
15,25\end{array}$ & $\begin{array}{c}21 \\
41 \\
38 \\
100\end{array}$ & 6 8 6 سنوات & حركى العميق الحس \\
\hline $\begin{array}{l}2,51945 \\
2,43300 \\
3,39400 \\
2,88997\end{array}$ & $\begin{array}{l}16,04 \\
16,07 \\
17,31 \\
16,54\end{array}$ & $\begin{array}{c}21 \\
41 \\
38 \\
100\end{array}$ & 6 8 6 سنوات 8 سنوات & حاسة البع \\
\hline $\begin{array}{l}2,46982 \\
3,12699 \\
2,33487 \\
2,70883\end{array}$ & $\begin{array}{l}16,00 \\
15,14 \\
15,18 \\
15,34\end{array}$ & $\begin{array}{c}21 \\
41 \\
38 \\
100\end{array}$ & 6 8 6 سنوات 7 سنوات & حاسة الشم \\
\hline $\begin{array}{l}1,53685 \\
2,27607 \\
2,25996 \\
2,16025\end{array}$ & $\begin{array}{l}12,80 \\
13,65 \\
13,97 \\
13,60\end{array}$ & $\begin{array}{c}21 \\
41 \\
38 \\
100\end{array}$ & 6 8 6 سنوات & حاسة التذوق \\
\hline $\begin{array}{l}10,56544 \\
11,77704 \\
11,03106 \\
11,34885\end{array}$ & $\begin{array}{l}105,14 \\
104,58 \\
109,21 \\
106,46\end{array}$ & $\begin{array}{c}21 \\
41 \\
38 \\
100\end{array}$ & 6 8 6 سنوات 8 سنوات & الدرجة الكلية \\
\hline
\end{tabular}


جدول (10) تحليل التباين أحادي الاتجاه

\begin{tabular}{|c|c|c|c|c|c|c|}
\hline مستوى & قيمة ف & متوسط & درجة & بحموع المربعات & مصدر التباين & الضطراب التباد \\
\hline غير دالة & 2,363 & $\begin{array}{c}12,977 \\
5,493\end{array}$ & $\begin{array}{c}2 \\
97 \\
99\end{array}$ & $\begin{array}{c}25,953 \\
532,797 \\
558,750\end{array}$ & داخل البمموعات & السمع \\
\hline غير دالة & 557, & $\begin{array}{l}3,331 \\
5,983\end{array}$ & $\begin{array}{c}2 \\
97 \\
99\end{array}$ & $\begin{array}{c}6,661 \\
580,379 \\
587,040\end{array}$ & داخل البمموعات & الدهليزية \\
\hline غير دالة & 2,217 & $\begin{array}{c}16,213 \\
7,313\end{array}$ & $\begin{array}{c}2 \\
97 \\
99\end{array}$ & $\begin{array}{c}32,426 \\
709,334 \\
741,760\end{array}$ & داخل البمموعات & اللمس \\
\hline غير دالة & 1,283 & $\begin{array}{c}10,812 \\
8,424\end{array}$ & $\begin{array}{c}2 \\
97 \\
99\end{array}$ & $\begin{array}{c}21,623 \\
817,127 \\
838,750\end{array}$ & داخل البمموعات & حاسة الحس حركى \\
\hline غير دالة & 2,265 & $\begin{array}{c}18,448 \\
8,144\end{array}$ & $\begin{array}{c}2 \\
97 \\
99\end{array}$ & $\begin{array}{c}36,897 \\
789,943 \\
826,840\end{array}$ & داخل البمموعات & حاسة البصر \\
\hline غير دالة & ,788, & $\begin{array}{l}5,804 \\
7,369\end{array}$ & $\begin{array}{c}2 \\
97 \\
99\end{array}$ & $\begin{array}{c}11,608 \\
714,832 \\
726,440\end{array}$ & داخل البمموعات البموعات & حاسة الشم \\
\hline غير دالة & 2,031 & $\begin{array}{l}9,284 \\
4,571\end{array}$ & $\begin{array}{c}2 \\
97 \\
99\end{array}$ & $\begin{array}{c}18,569 \\
443,431 \\
462,000\end{array}$ & داخل البمموعات البموعات & حاسة \\
\hline غير دالة & 1,848 & $\begin{array}{l}234,001 \\
126,627\end{array}$ & $\begin{array}{c}2 \\
97\end{array}$ & $\begin{array}{c}468,002 \\
12282,838\end{array}$ & بين البحموعات & الدرجة \\
\hline
\end{tabular}




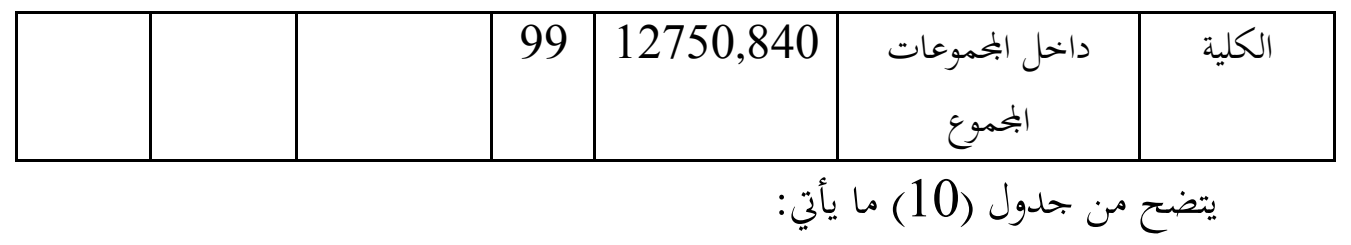

لا توجد فروق ذات دلالة إحصائية بين اضطراب التكامل الحسى لعينة البحث في ضوء

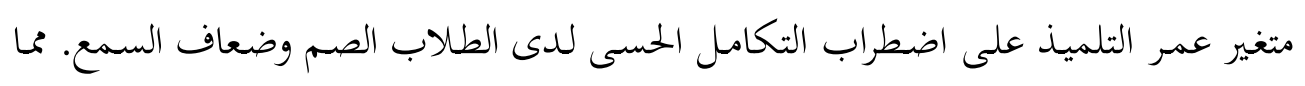
سبق يتضح صحة الفرض الرابع احصائيًا.

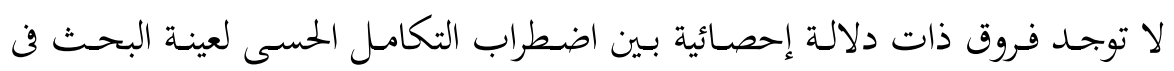
ضوء متغير عمر التلميذ على اضطراب التكامل الحسى ويرجع ذلك إلى أن الخلل في تنظيم

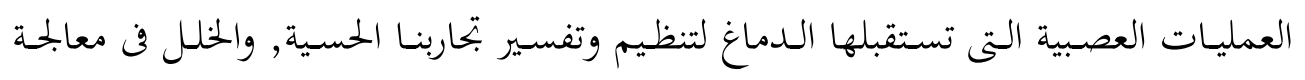
المعلومات التى تتلقاها أعيننا, آذاننا, جلدنا, مفاصلنا, أفواهنا, وأنوفنا وتوصيلها إلى أدمغتنا, وهـذه المعالجـات تمـر بمراحـل مختلفـة مـن الأنظمـة والأجهـزة الحسبية, وينتج عنها عـدم قـدرة الطفـل على تنظيم المـدخحات السـمعية والبصـرية, وعـدم القـدرة على تنظيم المـدخلات الدهليزية واللمسية, وعدم القدرة على تحديد الأولويات, وعدم القدرة على المرونة الحسية, وعـدم القدرة على التخطيط الحركى وجود ضعف أو افراط في اللمس أو الحركة أوالإبصار أوالأصـوات, ووجــود نشـاط عـالى أو مــنخفض بشـكل غـير عـادى, وضـعف في الأداء

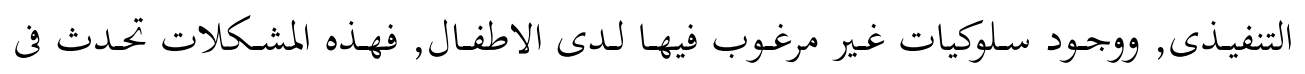

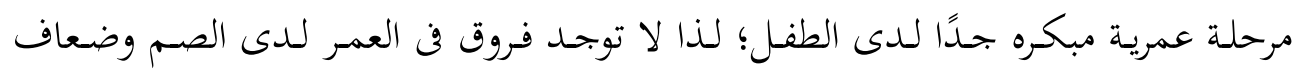
السمع في اضطراب التكامل الحسى لأنه يولد به وليس يكتسبه من البيئة . 


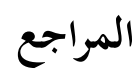

جمال محمد الحطيب (1997). الإعاقة السمعية. عمان: دائرة المكتبة الوطنية. عادل عبد الله عمد (2004). الإعاقات الحسية. القاهرة: دار الرشاد. عبد المطلب أمين القريطى(2001). سيكولوجية ذوى الاحتياجات الخحاصة وتربيتهم. القاهرة: دار الفكر العربى.

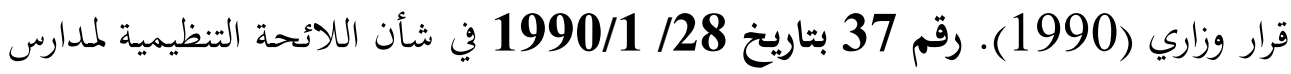
وفصول التربية الخاصة.

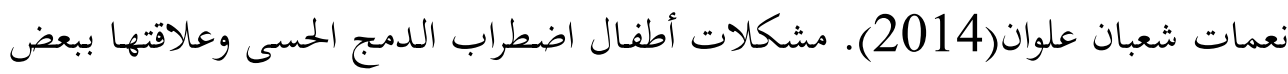

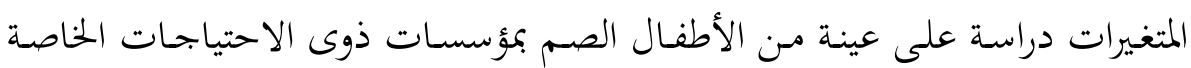

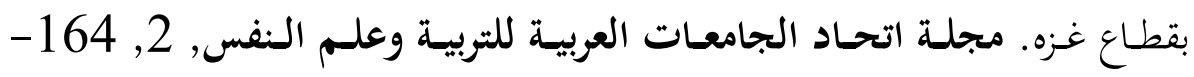
.192

Abraham, M. (2013). Addressing learning differences: Sensory integration: Practical strategies and sensory motor activities for use in the classroom. New York: Frank Schaffer Publications.

Akram, B. \& Hameed, A. (2014). Adaptive emotional abilities of adolescents with hearing impairment. Pakistan Journal of Psychological Research, 29(1), 103-123.

Albert,B., Selen,L., Verhagen,W., Pennings,R. \& Medendorp, W.(2018).Bayesian quantification of sensory reweighting in 
familial bilateral vestibular disorder. Journal of Neurophysiology, 119(3), 1209-1221.

Arnwine, B. (2005). Starting sensory integration therapy: fun activities that won't destroy your home or classroom. Future Horizons. U. S.A.

Ayres, A. (2005). Sensory integration and the child: Understanding hidden sensory challenges England: Western Psychological Services.

Batson, S., Kelly, K., Morrison, ～D., Virgin, F. (2019). Ophthalmologic abnormalities in children with congenital sensorineural hearing loss. J Binocul Vis Ocul Motil,17, 1- 5. doi: 10.1080/2576117X. 1625629.

Bergeson, T., Houston, D. \& Miyamoto, R. (2010).effects of congenital hearing loss and cochlear implantation on audiovisual speech perception in infants and children. Restorative Neurology Neuroscience, 28 (2), 157-169.

Bharadwaj, S., Daniel, L. \& Matzke, P. (2009). brief ReportSensory-processing disorder in children with cochlear implants. American Journal of Occupational Therapy, 63, 208-213.

Bharadwaj, S., Matzke, P. \& Daniel, L.(2012). multisensory processing in children with cochlear implants. International Journal of Pediatric Otorhinolaryngology, 76(6), 890-895.

Diekmann, H., Walger, M., Von Wedel, H. (1994). Sense of smell in deaf and blind patients. HNO, 42(5), 9-264.

Dimatties, M. \& Jennifer, S.(2003). Understanding sensory integration. ERIC Clearing House on Disabilities And gifted Education Arlington VA.

Gheysen, F. \& Loots, G.(2008). motor development of deaf children with and without cochlear Implants. Journal Student Deaf Education, 13(2),215-224.

Güdücü, Ç., Ergönül, İ., Öniz, A., İkiz, Ö., \& Özgören, M. (2019). Deaf Adolescents have bigger responses for somatosensory and visual stimulations. Neuroscience Letters, 134283 . doi: 10. 1016/j. neulet. 2019. 134283.

Guy, R., Nicholson, J., Pannu, S., \& Holden, R. (2003). A clinical evaluation of ophthalmic assessment in children with 
sensorineural deafness. Child: Care, Health and Development, 29, 377-384.

Hinchcliffe, A. (2007). Children with cerebral palsy: A manual for therapists, parents and community workers 2 ed. London: Sage Publications India Pvt Ltd.

Hollingsworth, R., Ludlow, A., Wilkins, A., Calver, R. \& Allen, P. (2014). Visual performance and ocular abnormalities in deaf children and young adults: a literature review. Acta Ophthalmologica, 92, 305 - 310. doi: 10.1111/aos.12302.

Isbell, C. \& Isbell, R. (2007). Sensory Integration: A Practical Guide for Preschool Teachers. Gryphon House, Inc.

Kegel, A., Dhooge, I. \& Waelvelde, H. (2008). Evenwicht, een belangrijk knelpunt in de motorische ontwikkeling van kinderen met een gehoorstoornis. Stimulus, 27(3), pp. 238250.

Kinnealey, M. \& Miller, L. (1993). Sensory integration learning disabilities occupational therapy. $8^{\text {th }}$. Philadelphia, PA: J.B. Lippincott .

Mafong, D., Pletcher, D, Hoyt, C., Lalwani, D. (2002). Ocular findings in children with congenital sensorineural hearing loss. Arch Otolaryngology Head Neck Surg, 128(11):13031306. doi:10.1001/archotol.128.11.1303.

Mahendra, S. \& Sulabha, M. (2012). Medico legal status of deaf persons in Indi Otolaryngology online, 2(1),1-19.

$\mathrm{NIH} /$ National Institute on Deafness and Other Communication Disorders. (2012, July 10). Deaf brain processes touch differently: Lacking sound input, the primary auditory cortex 'feels' touch. Science Daily. Retrieved July 6, 2019 from www. Science daily. com/ releases/ 2012/ 07/ 120710171733.htm.

Park, H., Byeon, K., Park, N., Kim, W., Lee, W., Han, K., Ban, J. (2017). Epidemiological association of olfactory dysfunction with hearing loss and dysphonia in the Korean population. Medicine, 96(47), e8890. doi: $10.1097 / \mathrm{md} .0000000000008890$.

Reebye, P. \& Stalker, A.(2008).Understanding Regulation Disorders of Sensory Processing in Children. London and Philadelphia. 
Schlumberger, E., Narbona, J. \& Manrique, M. ( 2004). nonverbal development of children with deafness with and without cochlear implants. Developmental Medicine Child Neurology, 46(9), 599-606.

Sharma, A., Melissa, R., David, H., Chi, D. (2009). Ophthalmologic findings in children with sensorineural hearing loss. Arch Otolaryngol Head Neck Surg. 135(2):119 -123. doi: 10.1001 /archoto

Simpson, P. (2013).Sensory Integration:" Now that makes sense". AUS: Author - House.

Suarez, H., Angeli, S., Rosales, B., Carrera, X. \& Alonso, R. (2007 ). balance sensory organization in children with profound hearing loss and cochlear implants. International Journal of Pediatric Otorhinolaryngology, 71(24), 629 637.

Trikakis, D., Curci, N \& Strom, H.(2003). Sensory Strategies for self-regulation: nonlinguistic body-based treatment for Deaf Psychiatric Patients. In N. Glickman \& S. Gulati (Eds.) Mental health care of deaf people: A culturally affirmative approach. Mahwah, New Jersey, US: Lawrence Erlbaum Associates, Inc.

Yogeswari, A., Subramanian, S., Sravya, M., Anandan, H. (2016). Prevalence of ophthalmic disorders in hearing impaired school children. International Journal of Scientific Study, 4 (6), 145-147. doi: 10. 17354/ ijss/2016/503. 